\title{
Tipos e eficiência de unidades de tratamento para água pluvial: revisão de literatura
}

\author{
Types and efficiency of rainwater treatment units: a \\ literature review
}

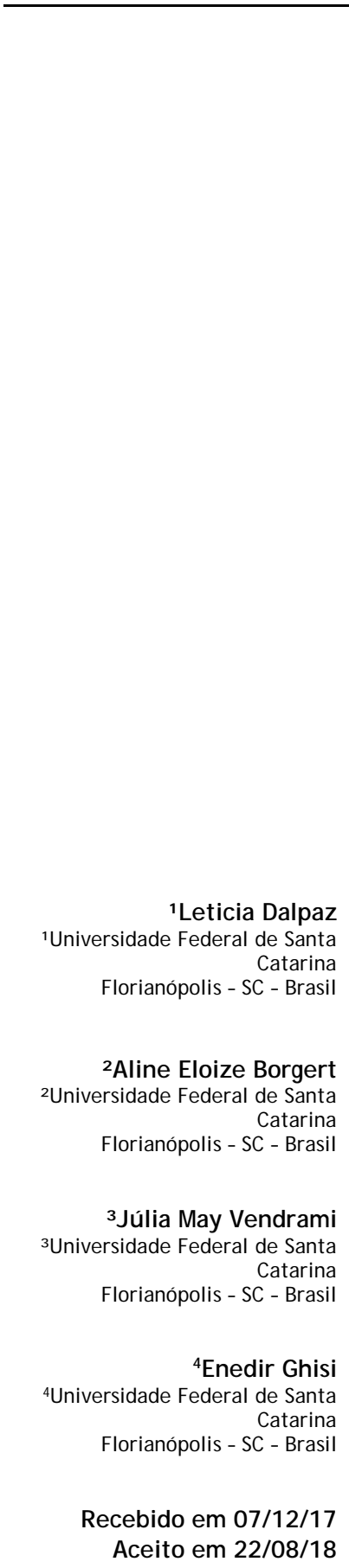

\section{Leticia Dalpaz \\ Aline Eloize Borgert \\ J úlia May Vendrami \\ Enedir Ghisi}

\section{Resumo}

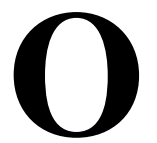

aproveitamento de água pluvial em edificações representa uma alternativa atraente como fonte de água. No entanto, para possibilitar sua utilização, a água pluvial deve ser tratada para atingir a qualidade necessária. Os filtros são bastante utilizados e aparecem em diversos modelos. Com o intuito de avaliar diferentes sistemas de filtragem, foi feita uma comparação entre os parâmetros obtidos com cada unidade de tratamento levantada e os valores recomendados pela ABNT (2007). Também foram comparadas as eficiências dos sistemas entre si. Para isso, uma revisão bibliográfica foi desenvolvida com base em pesquisa na literatura existente. Visouse organizar informações a respeito do estado da arte de unidades de tratamento de água pluvial no mundo e contribuir para a consolidação do uso desses sistemas. Identificou-se falta de padronização nos métodos e parâmetros, o que prejudica a análise precisa acerca de quais modelos seriam mais adequados para os possíveis cenários de utilização. Também foi constatado que o padrão de qualidade de água exigido na norma brasileira não foi atingido para nenhum caso. Entretanto, os modelos estudados mostraram resultados promissores, atingindo elevados percentuais de remoção, variando em sua maioria de $60 \%$ a $100 \%$.

Palavras-chave: Água pluvial. Filtragem. Tratamento. Filtros. Edificações. Revisão de literatura.

\section{Abstract}

The use of rainwater in buildings is an attractive alternative as a water source. However, to enable its use, rainwater must be treated in order to achieve the necessary quality. Filters are widely used for this purpose, and they are available in a variety of models. In order to assess different filtration systems, the results obtained by using each treatment unit and the limits recommended by ABNT (2007) were compared. The different systems' efficiency were also compared with each other. A review was undertaken based on research studies available in the literature. This project aimed to organize information on state-of-the-art treatment units around the world and to contribute to consolidate these systems of rainwater treatment. The study detected a lack of standardisation in the methods and parameters analysed, which hinders a more precise analysis of which models would be most suitable to treat rainwater. The study also verified that the water quality required by the Brazilian regulation was not achieved by any of the filters. Nevertheless, the models studied showed promising results, i.e., they achieved high efficiency for most parameters, ranging between $60 \%$ and $100 \%$.

Keywords: Rainwater. Filtration. Treatment. Filter. Buildings. Literature review. 


\section{Introdução}

O aumento da demanda de água em áreas urbanas tem ocasionado crescente busca pela utilização consciente deste recurso. O aproveitamento de água pluvial tem sido cada vez mais explorado como um meio viável de suprimento de água, principalmente em países em desenvolvimento (ADLER; HUDSON-EDWARDS; CAMPOS, 2011; AHAMMED; MEERA, 2006, 2010). Buscando a otimização dos sistemas de captação existentes, muitas pesquisas têm sido desenvolvidas para analisar características como a durabilidade, funcionalidade, viabilidade e eficácia dos mesmos (KIM et al., 2003; ADLER; HUDSON-EDWARDS; CAMPOS, 2011; CAMPISANO; MODICA, 2012; WANG et al., 2010).

Para Wang et al. (2010), armazenar e utilizar água pluvial é uma maneira efetiva de resolver problemas de abastecimento de água em cidades grandes. Entre 30\% e 40\% do consumo de água em residências é destinado para fins não potáveis, o que reflete o potencial de economia de água e os diversos benefícios que podem ser obtidos com o aproveitamento de água pluvial (NAKADA, 2012). Além disso, seu aproveitamento também é uma forma de economizar energia gasta com o tratamento centralizado e reduzir erosão e alagamento causados pelo escoamento da água pluvial sobre superfícies impermeáveis (KIM; LEE; KIM, 2003).

Em sua composição, é possível encontrar poluentes químicos e microrganismos, como poeira, partículas, compostos orgânicos halogenados, metais pesados, íons, microrganismos patogênicos e desreguladores endócrinos (AHAMMED; MEERA, 2006; AHAMMED; MEERA, 2010; KIM; LEE; KIM, 2005; ADLER; HUDSON-EDWARDS; CAMPOS, 2011). Conforme Adler, HudsonEdwards e Campos (2011) e Kwaadsteniet et al. (2013), esses poluentes são originados da atmosfera ou áreas de captação poluídas e tanques contaminados. Em consequência disso, seu consumo direto é desaconselhado pela Organização Mundial de Saúde (OMS). Outro aspecto negativo da coleta de água pluvial é sua instabilidade, uma vez que depende de condições meteorológicas e do clima, além de variações sazonais (KIM et al., 2003).

O tratamento da água pluvial é fundamental para seu aproveitamento (KIM et al., 2007; KIM et al., 2003; ADLER; HUDSON-EDWARDS; CAMPOS, 2011; JOHOR et al., 2017; KWAADSTENIET et al., 2013), e pode ser feito antes, durante ou depois do armazenamento (KIM et al., 2003). Em sistemas de captação domésticos, os filtros são geralmente empregados nas primeiras etapas do tratamento, impedindo o acúmulo de sedimentos ao longo do sistema. Eles podem ser instalados em qualquer ponto entre o telhado e os tanques, porém devem ser duráveis, fáceis de limpar e economicamente viáveis (KIM et al., 2007).

Segundo Kim, Lee e Kim (2005), para o tratamento da água pluvial, além de verificar a quantidade de micróbios, é importante analisar também outros poluentes, visto que podem causar problemas técnicos nos aparelhos hidráulicos, comprometer a qualidade da água para utilização em limpeza, ou até mesmo gerar barreiras psicológicas pelos consumidores da água tratada.

Com o crescente interesse no aproveitamento de água pluvial, diversos modelos de filtros têm surgido no mercado. Dentre os diferentes tipos, é possível encontrar modelos que não utilizam energia elétrica, são autolimpantes, exigem pouca manutenção, de fluxo ascendente ou descendente, entre outras características. Há ainda estudos que analisam filtros que são compostos por materiais inovadores, como concreto permeável, ou até mesmo camadas de solos presentes nos telhados verdes. Dessa forma, é imprescindível que estudos sejam desenvolvidos para comparar as diferentes tecnologias existentes. Ao longo do desenvolvimento deste artigo nenhum trabalho semelhante foi encontrado na literatura.

O objetivo principal deste estudo é analisar, por meio de revisão bibliográfica, os diferentes modelos e a eficiência das unidades de tratamento utilizadas para o tratamento de água pluvial para fins não potáveis em edificações. Também buscase comparar a qualidade final da água para cada unidade de tratamento com a qualidade exigida pela NBR 15527 (ABNT, 2007) para usos restritivos não potáveis.

\section{Método}

O método de desenvolvimento utilizado neste artigo é baseado em revisão bibliográfica de artigos científicos que buscaram analisar a eficiência de diferentes unidades de tratamento ${ }^{1}$ utilizadas no sistema de aproveitamento de água pluvial para uso doméstico. Para se obter uma visão ampla sobre o tema, foram analisados métodos de filtragem distintos, buscando

${ }^{1}$ Leitura internacional. Os nomes dos modelos foram traduzidos de forma livre pelos autores. 
informações em artigos de periódicos, revistas, anais e dissertações, tanto internacionais quanto nacionais. A data das publicações não foi um fator determinante para a escolha dos artigos utilizados e a amostra obtida abrange materiais dos últimos vinte anos, incluindo informações publicadas no ano de 2017. Por meio da leitura desses artigos, foram obtidos dados quantitativos e qualitativos sobre o aproveitamento de água pluvial, tornando possível avaliar a eficiência e o funcionamento de cada unidade de tratamento.

Inicialmente, é apresentada uma breve caracterização de cada unidade de tratamento, com a explanação do seu método de funcionamento, quais princípios são utilizados e a forma como o sistema foi implantado. São também expostos os métodos de análise, testes e experimentos realizados e equipamentos utilizados, desde que constem na fonte original.

Posteriormente, serão ilustradas em uma tabela as características do afluente e do efluente, bem como o percentual de variação de cada parâmetro. O percentual de variação será estabelecido por meio da porcentagem do valor respectivo ao parâmetro analisado no efluente em relação ao afluente. Com isso, valores negativos representam redução e valores positivos o aumento do valor absoluto do parâmetro avaliado. Caso o sistema possua um método de desinfecção ${ }^{2}$ atuando em conjunto, deverá ser considerada sua colaboração e mostrados os resultados do processo para o filtro com e sem este método. Assim, será elaborada uma breve conclusão sobre a unidade de tratamento estudado, na qual deve constar se os critérios de qualidade da água definidos no início da pesquisa foram satisfeitos.

A ABNT (2007) foi utilizada como base para a definição do padrão de qualidade da água exigido, conforme os critérios apresentados na Tabela 1. A qualidade do efluente obtida em cada sistema foi comparada com o padrão apresentado em norma a fim de avaliar se a mesma se enquadra nos limites estabelecidos. Para comparar a eficiência entre as unidades de tratamento, foram confrontados os percentuais de variação obtidos para cada parâmetro. Como os dados disponíveis dependem das análises feitas previamente para cada unidade de tratamento, a existência e o uso do parâmetro para comparação dependerá dos estudos desenvolvidos.

\section{Unidades de tratamento para água pluvial}

Um sistema de tratamento de água pluvial é composto basicamente pela área de captação da água, um processo de tratamento e o local de armazenamento. A água oriunda de chuvas normalmente não exige formas de tratamento tão complexas, por conter menos poluentes do que a água cinza, por exemplo.

O processo de tratamento é composto por duas etapas: o descarte da água de escoamento inicial e a passagem pelo filtro. A primeira etapa é essencial para manter o bom funcionamento do filtro e a qualidade da água armazenada, pois evita o acúmulo de sedimentos ao longo do sistema. A água inicialmente coletada apresenta maiores concentrações de partículas sólidas e contaminantes, pois atua na limpeza da área de coleta e do próprio sistema de captação.

A segunda etapa, composta pela filtragem, consiste em uma operação física ou mecânica usada para separar sólidos de fluidos através da inserção de um meio filtrante por onde apenas o fluido pode passar (LANDAGE; WASIF; SAPKAL, 2013). Alguns filtros contam ainda com dispositivos que promovem a desinfecção microbiológica da água por meio da adição de agentes desinfectantes ou pela alteração do material do próprio meio filtrante.

A seguir estão apresentadas as unidades de tratamento analisadas conforme o método descrito anteriormente. Cada tópico apresentado faz referência a um sistema diferente, de forma a tornar possível a comparação da taxa de remoção com base na qualidade de água pluvial coletada para cada experimento.

\section{Fibras lignocelulósicas}

Kim et al. (2007) e Kim et al. (2003) analisaram um filtro feito com fibras de madeira reciclada. O dispositivo consiste em um tanque decantador inicial e um tanque de separação contendo o meio filtrante, conforme mostrado na Figura 1.

Esse sistema é projetado para fazer o tratamento da água de escoamento inicial. Toda água entra no tanque decantador e passa pelo meio filtrante quando a entrada for larga e/ou a taxa de fluxo de

${ }^{2} 0$ termo desinfecção está sendo utilizado nesse artigo com o significado de promoção da destruição parcial ou completa de microrganismos patogênicos. 
entrada for baixa. Por outro lado, a água não passará pela unidade de filtragem quando houver alta taxa de fluxo de água. O sistema pode ser controlado facilmente por meio do ajuste do tamanho da entrada. Modificações químicas na unidade de tratamento usando óxido de alumínio foram feitas para melhorar a remoção de fosfato e metais pesados.

As amostras foram tratadas a uma velocidade de fluxo de $11 \mathrm{~mm} / \mathrm{min}$. A eficiência do sistema foi examinada analisando nitrogênio, fosfato e turbidez. A Tabela 2 apresenta os resultados dos parâmetros analisados antes e depois do tratamento das amostras.

O sistema com fibras lignocelulósicas remove os poluentes e os íons solúveis por mecanismos de troca de íons: a reação de troca de cátions remove os metais e a de troca dos ânions remove nitrogênio e fosfato. A utilização de dois estágios de filtragem, que consistem na precipitação e coleta nas fibras, também ajuda a diminuir os contaminantes da água.

O filtro de fibras é útil para remover alguns poluentes da água, mas sua qualidade ainda não suficiente para a água ser usada para pulverização, limpeza e descarga de vaso sanitário. Entretanto, ele removeu não somente partículas, mas também nutrientes como nitrogênio e fosfato. Dentre os parâmetros analisados e citados em ABNT (2007), a turbidez se manteve dentro do valor exigido para usos restritivos, tanto antes quanto depois da filtragem.

Tabela 1 - Parâmetros de qualidade de água pluvial para usos restritivos não potáveis

\begin{tabular}{|c|c|c|}
\hline Parâmetro & Análise & Valor \\
\hline Coliformes totais & Semestral & Ausência em 100 mL \\
\hline Coliformes fecais & Semestral & Ausência em 100 mL \\
\hline Cloro residual livre $^{a}$ & Mensal & 0,5 a $3,0 \mathrm{mg} / \mathrm{L}$ \\
\hline Turbidez & Mensal & $\begin{array}{l}<2,0 \mathrm{uT}^{\mathrm{c}}, \\
\text { para usos menos restritivos }<5,0 \mathrm{uT}\end{array}$ \\
\hline Cor aparente & Mensal & $<15 \mathrm{uH}^{\mathrm{d}}$ \\
\hline $\begin{array}{l}\text { Deve prever ajuste de } \mathrm{pH} \text { para proteção } \\
\text { das redes de distribuição, caso necessário }\end{array}$ & Mensal & $\begin{array}{l}\mathrm{pH} \text { de } 6,0 \text { a } 8,0 \text { no caso de tubulação de } \\
\text { aço carbono ou galvanizado }\end{array}$ \\
\hline
\end{tabular}

Fonte: baseado em ABNT (2007).

Nota: podem ser usados outros métodos para desinfecção além da adição de cloro, como aplicação de raio ultravioleta e aplicação de ozônio.

Legenda:

a No caso de serem utilizados compostos de cloro para desinfecção;

b Caso não seja utilizado nenhum corante, ou antes da sua utilização;

c UT - unidade de Turbidez, definida pela presença de material coloidal em suspensão; e

$\mathrm{d}$ uH - unidade de Hazen (mg Pt Co/ L ou mg/L de Pt).

Figura 1 - Esquema representativo da unidade de tratamento com fibras lignocelulósicas

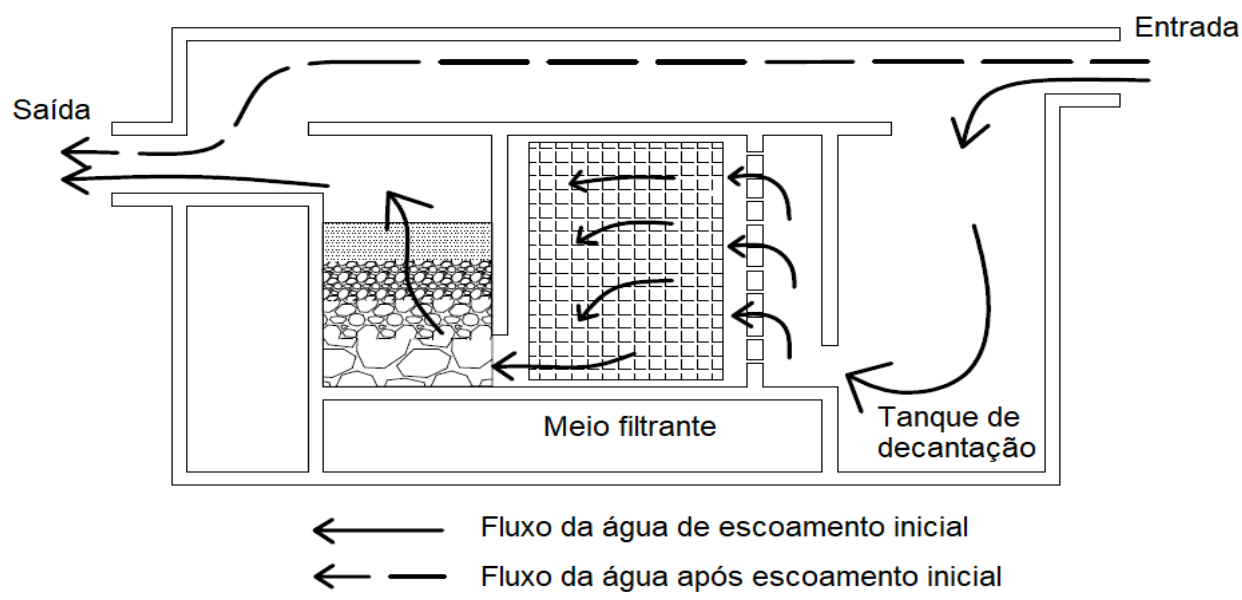

Fonte: baseado em Kim et al. (2007). 
Tabela 2 - Qualidade da água do afluente e efluente do sistema de fibras lignocelulósicas

\begin{tabular}{l|c|c|c|c|c}
\hline \multirow{2}{*}{ Parâmetro } & \multicolumn{5}{c}{ Sistema de Fibras Lignocelulósicas } \\
\cline { 2 - 6 } & \multirow{2}{*}{ Afluente } & Fibra não-modificada & Modificada quimicamente \\
\cline { 3 - 6 } & & Efluente & Variação & Efluente & Variação \\
\hline Turbidez (NTU) & 0,88 & - & - & 0,59 & $-33 \%$ \\
Demanda química de oxigênio (mg/L) & 192 & 110 & $-43 \%$ & 150 & $-22 \%$ \\
Fosfato (mg/L) & 4 & 3,9 & $-2 \%$ & 1,7 & $-58 \%$ \\
Nitrogênio (mg/L) & 9 & 8 & $-11 \%$ & 7 & $-22 \%$ \\
Cobre (mg/L) & 1,7 & 2,2 & $29 \%$ & 0,94 & $-45 \%$ \\
Ferro (mg/L) & 3,2 & 3,3 & $3 \%$ & 0,53 & $-83 \%$ \\
Zinco (mg/L) & 0,09 & 0,056 & $-38 \%$ & 0,055 & $-39 \%$ \\
Turbidez (uTc) & 0,88 & - & - & 0,59 & $-33 \%$ \\
\hline
\end{tabular}

Fonte: baseado em Kim et al. (2003, 2007).

\section{Membrana metálica}

Kim et al. (2003, 2007) e Kim, Lee e Kim (2005) analisaram um filtro de membrana metálica que se destaca por ser durável quando submetido a alta pressão (1MPa), altas temperaturas $\left(350{ }^{\circ} \mathrm{C}\right)$, oxidação química e choques externos. Além disso, as membranas não são danificadas se permanecerem secas, visto que a coleta de água pode ocorrer com menor intensidade em alguns períodos, e sua vida útil é consideravelmente maior. A possibilidade de apresentar grande fluxo ( $>1000 \mathrm{~L} / \mathrm{m}^{2} \mathrm{~h}$ ), baixo custo, longa vida útil e fácil operação das membranas de metal feitas de aço inoxidável são características que tornam esse filtro bastante interessante (KIM et al., 2007).

O filtro de membrana metálica (MMF, na sigla em inglês) analisado por Kim et al. (2003, 2007) e Kim, Lee e Kim (2005) é comercializado em três tamanhos de poro, de raios nominais de $5 \mu \mathrm{m}, 1 \mu \mathrm{m}$ e $0,5 \mu \mathrm{m}$. Todos têm comprimento de filtragem igual a $0,222 \mathrm{~m}$ e área da membrana igual a $9,76 \times 10^{-3} \mathrm{~m}^{2}$. A resistência das membranas dos filtros de $1 \mu \mathrm{m}$ e $0,5 \mu \mathrm{m}$ é $1,04 \times 10^{10} \mathrm{~m}^{-1}$ e a do filtro de $5 \mu \mathrm{m}$ é $1,01 \times 10^{10} \mathrm{~m}^{-1}$. Kim et al. (2003) e Kim, Lee e Kim (2005) analisaram esse sistema por meio dos mesmos métodos descritos em Kim et al. (2007).

A Tabela 3 mostra a comparação da qualidade da água do afluente com a filtrada pela membrana metálica. Para a análise da remoção de partículas, ilustrada na Tabela 4, somente tamanhos entre 2 e $15 \mu \mathrm{m}$ foram considerados. É provável que o tamanho efetivo dos poros seja maior que seu tamanho nominal.
A eficiência da diminuição da turbidez variou entre $18 \%$ e $54 \%$ e a diferença na cor da água é desprezível. Geralmente a eficiência de remoção aumenta com a diminuição do tamanho nominal dos poros. Para os parâmetros analisados, os filtros atendem aos critérios de turbidez, cor aparente e pH estabelecidos; em relação aos coliformes totais, a membrana de $1 \mu \mathrm{m}$ atingiu quantidades muito pequenas. Não foi analisada a quantidade de coliformes totais para o filtro de $0,5 \mu \mathrm{m}$. O filtro de membrana metálica reteve eficientemente as partículas presentes na água e o modelo com poros maiores demorou mais para entupir, porém reteve menos partículas. Os valores obtidos para turbidez e cor aparente estavam dentro dos limites estabelecidos pela ABNT (2007) para usos mais restritivos, mesmo antes da filtragem. Contudo, os resultados para coliformes totais não obtiveram a remoção total, apesar de terem atingido valores baixos, principalmente para a membrana de $1 \mu \mathrm{m}$.

\section{Membrana metálica com ozonização}

Kim et al. (2003) e Kim, Lee e Kim (2005) analisaram um sistema de filtragem com membranas de metal imersas em um aerador de ozônio. É possível utilizar a membrana metálica em conjunto com o ozônio devido à sua excelente estabilidade química, o que mantém a qualidade da membrana de metal citada anteriormente, além de possuir o benefício de reduzir o entupimento da membrana e melhorar a qualidade da água filtrada devido ao seu efeito desinfectante. O sistema foi assim elaborado com o objetivo de remover os contaminantes enquanto mantém alto fluxo e baixa pressão transmembrana e também para examinar o efeito da desinfecção.

\footnotetext{
${ }^{3} 0$ parâmetro de Turbidez foi estimado a partir de gráfico retirado de uma pesquisa sobre este sistema realizada pelo mesmo autor no ano de 2007. Nela, não foi analisado o filtro sem modificação química das fibras.
} 
Tabela 3 - Qualidade da água do afluente e filtrada pelo filtro de membrana metálica

\begin{tabular}{|c|c|c|c|c|c|c|c|}
\hline \multirow{3}{*}{ Parâmetro } & \multicolumn{7}{|c|}{ Filtro de Membrana Metálica } \\
\hline & \multirow{2}{*}{ Afluente } & \multicolumn{2}{|c|}{$5 \mu \mathrm{m}$} & \multicolumn{2}{|c|}{$1 \mu \mathrm{m}$} & \multicolumn{2}{|c|}{$0,5 \mu \mathrm{m}$} \\
\hline & & Efluente & Variação & Efluente & Variação & Efluente & Variação \\
\hline $\begin{array}{l}\text { Coliformes totais } \\
(\mathrm{mg} / \mathrm{L})\end{array}$ & 130,6 & 28,7 & $-78 \%$ & 2,5 & $-98 \%$ & - & - \\
\hline Turbidez (uT) & 1,19 & 0,98 & $-18 \%$ & 0,948 & $-20 \%$ & 0,55 & $-54 \%$ \\
\hline Cor (uH) & 12 & 12 & $0 \%$ & 12 & $0 \%$ & 11 & $-8 \%$ \\
\hline $\mathrm{pH}$ & 7,57 & 7,52 & $-1 \%$ & 7,49 & $-1 \%$ & 7,18 & $-5 \%$ \\
\hline $\begin{array}{l}\text { Demanda química } \\
\text { de oxigênio (mg/L) }\end{array}$ & 6,1 & 2,5 & $-59 \%$ & 2,7 & $-56 \%$ & 2 & $-67 \%$ \\
\hline $\begin{array}{l}\text { Condutividade } \\
\text { elétrica }(\mu \mathrm{S} / \mathrm{cm})\end{array}$ & 82,6 & 82,4 & $0 \%$ & 82,2 & $0 \%$ & 87 & $5 \%$ \\
\hline
\end{tabular}

Fonte: baseado em Kim et al. (2003, 2007).

Tabela 4 - Remoção de partículas pelo filtro de membrana metálica

\begin{tabular}{l|c|c|c}
\hline \multirow{2}{*}{\multicolumn{1}{c|}{ Parâmetro }} & \multicolumn{3}{|c}{ Filtro de Membrana Metálica } \\
\cline { 2 - 4 } & $\mathbf{5} \boldsymbol{\mu m}$ & $\mathbf{1} \boldsymbol{\mu m}$ & $\mathbf{0 , 5} \boldsymbol{\mu m}$ \\
\cline { 2 - 4 } & Efluente & Efluente & Efluente \\
\hline Retenção de partículas 2 $\mu \mathrm{m}$ & $39 \%$ & $48 \%$ & $52 \%$ \\
Retenção de partículas 3 $\mu \mathrm{m}$ & $43 \%$ & $51 \%$ & $54 \%$ \\
Retenção de partículas 5 $\mu \mathrm{m}$ & $59 \%$ & $65 \%$ & $67 \%$ \\
Retenção de partículas $8 \mu \mathrm{m}$ & $70 \%$ & $71 \%$ & $78 \%$ \\
Retenção de partículas 10 $\mu \mathrm{m}$ & $77 \%$ & $79 \%$ & $82 \%$ \\
Retenção de partículas 15 $\mu \mathrm{m}$ & $82 \%$ & $90 \%$ & $86 \%$ \\
\hline
\end{tabular}

Fonte: baseado em Kim et al. (2007).

Para o estudo foram coletadas amostras do escoamento de um telhado comum. O reator cilíndrico utilizado tem capacidade de trabalho de 5 litros e a injeção de ozônio ocorreu pela parte inferior do sistema, conforme ilustrado na Figura 2. Com o objetivo de otimizar o funcionamento do filtro, a pressão transmembrana aumentou gradativamente de $500 \mathrm{~L} / \mathrm{m}^{2} \mathrm{~h}$ para $3000 \mathrm{~L} / \mathrm{m}^{2} \mathrm{~h}$.

Foram comparados filtros de membranas metálicas de $1 \mu \mathrm{m}$ e $5 \mu \mathrm{m}$, com a adição de um gerador de ozônio, com dosagem de 2,58g/h. A pressão transmembrana foi monitorada e os procedimentos de análise dos parâmetros e as características das membranas são idênticos aos descritos anteriormente. Somente a quantidade de coliformes foi analisada, pois o objetivo do sistema é implementar uma opção de desinfecção e diminuir a pressão transmembrana. O monitoramento foi realizado durante cinco eventos de chuva, com a média dos valores e os resultados dos testes expostos na Tabela 5.

As membranas metálicas combinadas com tratamento de ozônio durante 1 minuto obtiveram a inativação quase total de coliformes, sugerindo que esse sistema tem o potencial de controle microbiano. Dessa forma, ao compararem-se os resultados deste sistema com o anterior, verificouse que as duas membranas metálicas são eficientes para tratar a água pluvial e que a inserção de ozônio provocou redução significativa na pressão transmembrana resultante do entupimento da membrana. Isto se deve provavelmente ao efeito do ozônio na água de destruir a matéria orgânica e desestabilizar os colóides. Assim, em termos de eliminação de microrganismos e prevenção ao entupimento, conclui-se que a adição do ozônio torna o sistema muito mais eficiente, atingindo a ausência de coliformes totais requerida pela ABNT (2007) para a membrana de $1 \mu \mathrm{m}$. Entretanto, sua utilização provoca o encarecimento do processo de tratamento quando comparado com um sistema convencional com cloro.

\section{Íons de Prata}

Adler, Hudson-Edwards e Campos (2011) analisaram o uso de íons de prata associado a um sistema convencional de filtragem como um modelo de purificação de água pluvial, aplicável em pequenas escalas. Foram instalados nove sistemas na região semiárida do município de San Miguel de Allende, México. 
Figura 2 - Esquema representativo do filtro de membrana metálica

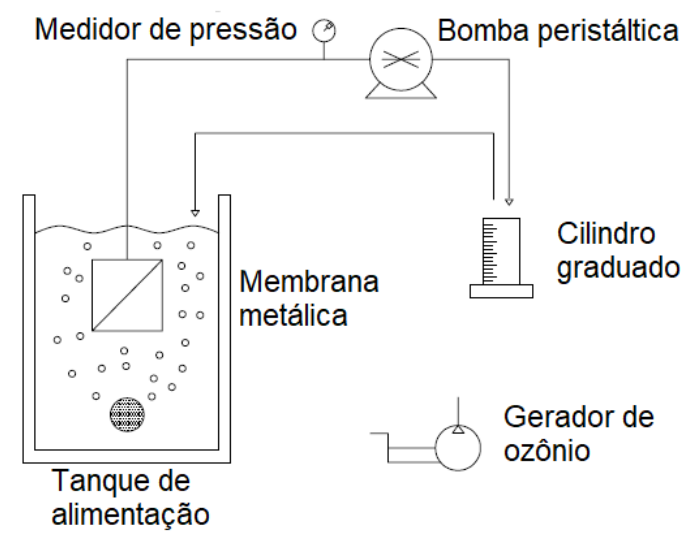

Fonte: baseado em Kim et al. (2003).

Tabela 5 - Qualidade da água do afluente e filtrada pelo filtro de membrana metálica com ozonização

\begin{tabular}{l|c|c|c|c|c}
\hline \multirow{2}{*}{ Parâmetro } & \multicolumn{4}{|c}{ Filtro de Membrana Metálica com Ozonização } \\
\cline { 2 - 6 } & \multirow{2}{*}{ Afluente } & \multicolumn{2}{|c}{$\mathbf{5} \boldsymbol{\mu m}$} & \multicolumn{2}{c}{$\mathbf{1} \boldsymbol{\mu m}$} \\
\cline { 3 - 6 } & & Efluente & Variação & Efluente & Variação \\
\hline Coliformes totais (mg/L) & 130,6 & 1,1 & $-99 \%$ & 0 & $-100 \%$ \\
\hline
\end{tabular}

Fonte: baseado em Kim et al. (2005).

O modelo desenvolvido, conforme ilustrado na Figura 3, é composto por um tanque de decantação, uma cisterna, um filtro de aço inoxidável para remoção de partículas maiores que $100 \mu \mathrm{m}$, uma unidade de ionização de prata, na qual são feitas pequenas descargas elétricas em um par de eletrodos, liberando íons de prata, e por um filtro contendo uma mistura de carvão ativado e 'fluxo de degradação cinética' do inglês Kinetic Degradation Fluxion (KDF).

Para cada sistema existem algumas pequenas variações, visto que possuem áreas de captação e consumo diferentes e que foram construídos em períodos distintos, ao longo de dois anos. Além disso, dois sistemas (número 5 e 7) não seguiram a estrutura citada acima: para o primeiro, utilizaramse partículas coloidais de prata no tanque de armazenamento de água, enquanto no segundo, o sistema de filtragem utilizado foi de osmose reversa.

As amostras de água foram coletadas do tanque de decantação, que contém a água de escoamento inicial, da cisterna e dos pontos de consumo utilizados diretamente pelos usuários. Contudo, não foi possível fazer a coleta de todos os pontos selecionados em todos os modelos instalados. A Tabela 6 apresenta o valor médio das amostras coletadas para a etapa de decantação, comparandose a qualidade da água do tanque com a da cisterna, e para o processo de ionização e filtragem, obtido das amostras entre a cisterna e os pontos de utilização. Na Tabela 7 são apresentadas as quantidades de coliformes totais e as porcentagens de redução de alguns dos sistema implantados, para as etapas de decantação e de ionização com filtração.

Apenas os sistemas 7 e 8 atingiram valor nulo para coliformes fecais, conforme exigido pela ABNT (2007), ainda que os sistemas 2, 5 e 6 também obtiveram pequenos valores e altas taxas de remoção para este parâmetro. Em algumas instalações, o índice de coliformes apresentou-se nulo em todos os pontos de coleta, sugerindo uma condição de telhado limpa e afastada de possíveis agentes contaminantes. Todos os sistemas, com exceção do número 9, obtiveram alta eficiência para desinfecção da água pluvial, apresentando índice de coliformes inferior ao determinado pela Organização Mundial de Saúde (OMS), sendo, portanto, viável para o uso como água potável.

A combinação de íons de prata com um sistema de filtragem comum mostrou-se efetiva para o tratamento de água pluvial. Contudo, devido à falha ocorrida no sistema número 9, não é possível garantir que o modelo apresente o potencial necessário para prover água potável. Entretanto, é necessário levar em consideração que a concentração de prata utilizada (inferior a 5ppb) foi muito inferior ao permitido pela OMS, sendo comum utilizar concentrações pelo menos dez vezes maiores no tratamento de águas. 
Figura 3 - Esquema representativo do sistema com íons de prata

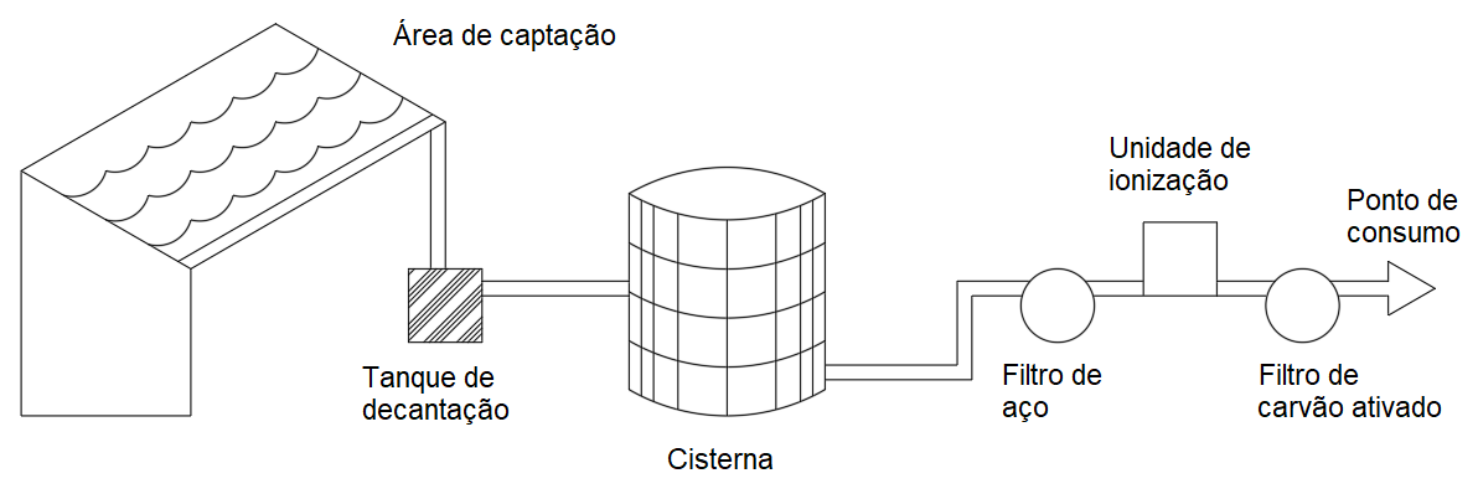

Fonte: baseado em Adler, Hudson-Edwards e Campos (2011).

Tabela 6 - Qualidade da água do afluente e após passar pela etapa de decantação do sistema de íons de prata

\begin{tabular}{l|c|c|c|c|c|c}
\hline \multirow{2}{*}{\multicolumn{1}{c|}{ Parâmetro }} & \multicolumn{5}{c}{ Sistema com Íons de Prata } \\
\cline { 2 - 7 } & \multicolumn{3}{c}{ Decantação } & \multicolumn{3}{c}{ Ionização e Filtragem } \\
\cline { 2 - 7 } & Afluente & Efluente & Variação & Afluente & Efluente & Variação \\
\hline $\mathrm{pH}$ & 6,4 & 6,6 & $3 \%$ & 6,6 & 6,8 & $3 \%$ \\
Alcalinidade (mg/L) & 65,7 & 77,8 & $18 \%$ & 77,8 & 73,3 & $-6 \%$ \\
Dureza (mg/L) & 65,7 & 80,6 & $23 \%$ & 80,6 & 67,8 & $-16 \%$ \\
Demanda química de oxigênio & 108,0 & 83,3 & $-23 \%$ & 83,3 & 110,0 & $32 \%$ \\
(mg/L) & 3,5 & 3,8 & $9 \%$ & 3,8 & 2,8 & $-26 \%$ \\
Oxigênio dissolvido (mg/L) & 47,9 & 11,0 & $-77 \%$ & 11,0 & 6,4 & $-42 \%$ \\
Condutividade elétrica $(\mu \mathrm{S} / \mathrm{cm})$ & & & & & \\
\hline
\end{tabular}

Fonte: baseado em Adler, Hudson-Edwards e Campos (2011).

Tabela 7 - Resultado da análise de coliformes totais para as etapas do sistema

\begin{tabular}{c|c|c|c|c|c|c}
\hline \multirow{2}{*}{$\begin{array}{c}\text { Número do } \\
\text { sistema }\end{array}$} & \multicolumn{6}{|c}{ Coliformes totais (CFU/mL) } \\
\cline { 2 - 7 } & Afluente & Efluente & Variação & Afluente & Efluente & Variação \\
\cline { 2 - 7 } & 550 & 6 & $-99 \%$ & 6 & 4 & $-33 \%$ \\
5 & 8 & 3 & $-63 \%$ & 3 & 3 & $0 \%$ \\
6 & 1650 & 26 & $-98 \%$ & 26 & 2 & $-92 \%$ \\
7 & 119 & 17 & $-86 \%$ & 17 & 0 & $-100 \%$ \\
8 & $\mathrm{ND}$ & 3 & - & 3 & 0 & $-100 \%$ \\
9 & $>2600$ & ME & - & ME & ME & - \\
\hline ND - não disponível. \\
ME - muito elevado para contar.
\end{tabular}

Fonte: baseado em Adler, Hudson-Edwards e Campos (2011).

Legenda:

ND - não disponível; e

ME - muito elevado para contar.

\section{Filtro de pressão}

Nakada (2012) estudou a viabilidade do uso de água pluvial através da coleta direta de um telhado de fibrocimento e um cerâmico de mesma dimensão. As amostras foram coletadas entre o período de 23 de março de 2010 até 26 de abril de 2012. O filtro analisado possui área filtrante de $0,06 \mathrm{~m}^{2}$, diâmetro de $280 \mathrm{~mm}$ e capacidade para 25kg de areia com três meios filtrantes diferentes. A passagem de água pelo filtro é mostrada na Figura 4.

Dois tipos de areia e um antracito foram utilizados como meios filtrantes, sendo desenvolvidos três modelos de filtros. O filtro 1 foi preenchido com $38 \mathrm{~cm}$ de areia fina, o filtro $2 \mathrm{com} 38 \mathrm{~cm}$ de areia média e o filtro $3 \mathrm{com} 15,2 \mathrm{~cm}$ de antracito, $11,4 \mathrm{~cm}$ 
de areia fina e $11,4 \mathrm{~cm}$ de areia grossa, de cima para baixo. A Figura 5 apresenta as camadas finais de cada filtro. Os parâmetros analisados seguiram as indicações da American Public Health Association (2005).

A água pluvial foi coletada sem descarte do escoamento inicial e submetida à filtração com taxa de aplicação superficial de $450 \mathrm{~m} 3 / \mathrm{m} 2$ dia. Foram testados como coagulantes dois tipos de amido de milho, um não iônico e um catiônico, e uma solução de cloreto férrico. O coagulante selecionado para análise foi o de amido de milho catiônico, com uma dosagem de $6 \mathrm{mg} / \mathrm{L}$. A Tabela 8 apresenta as taxas de redução obtidas em cada filtro e a qualidade do afluente considerado. Observou-se que a qualidade final obtida pelos três filtros não atingiu os parâmetros exigidos pela ABNT (2007). Percebe-se que o filtro 1 apresentou maior eficiência para sólidos suspensos, sólidos dissolvidos, sólidos totais e turbidez. Para os parâmetros cor e temperatura as maiores reduções foram observadas no filtro 2, enquanto que para coliformes totais e Escherichia coli foram no filtro 3. Além da análise dos filtros desenvolvidos, foi possível perceber que cada precipitação apresenta características particulares, dependente, de forma significativa, do período de estiagem antecedente ao evento de precipitação.

\section{Rede de náilon e rede metálica}

Cientes de que o escoamento inicial de água contém concentrações de poluentes muito maiores que o escoamento posterior, Wang et al. (2010) analisaram meios filtrantes de rede de náilon, rede metálica e a combinação dos dois.

Para a análise, foi utilizada uma amostra de $3 \mathrm{~m}^{3}$, obtida por meio da mistura de água de torneira

com sujeira para simular a qualidade dos primeiros escoamentos de telhado. A água foi armazenada em um tanque de metal com dimensão da base de $100 \mathrm{~cm}$ por $200 \mathrm{~cm}$ e altura de $100 \mathrm{~cm}$ por 24 horas, para eliminar o impacto do cloro residual. Quando a válvula de saída foi acionada, a água pôde escoar por uma trincheira construída com alvenaria de tijolos com acabamento em argamassa com base de $10 \mathrm{~cm}$ por $3000 \mathrm{~cm}$ e altura de $60 \mathrm{~cm}$, com a velocidade de escoamento controlada, passando pelo meio filtrante. A cada 5 segundos, uma amostra do efluente foi coletada para análise. Para evitar a sedimentação das partículas no tanque, foi utilizado um misturador.

\section{Figura 4 - Esquema representativo do filtro de pressão}

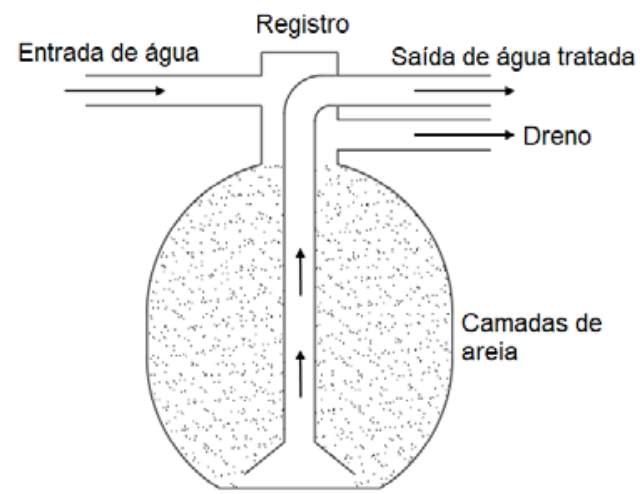

Fonte: adaptado do manual do fabricante (NAKADA, 2012).

Figura 5 - Representação dos três modelos de filtro utilizados

Filtro 1

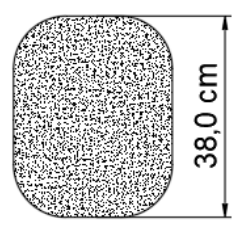

Areia fina

Filtro 2

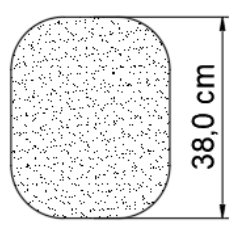

Legenda

Fonte: baseado em Nakada (2012).

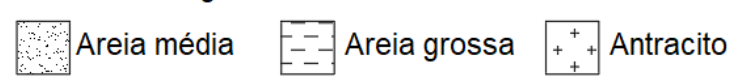

Filtro 3

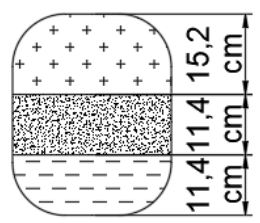

잉 
Tabela 8 - Qualidade da água do afluente e filtrada pelo filtro de pressão com amido de milho catiônico a $6 \mathrm{mg} / \mathrm{L}$

\begin{tabular}{|c|c|c|c|c|c|c|c|}
\hline \multirow{3}{*}{ Parâmetros } & \multicolumn{7}{|c|}{ Filtro de Pressão } \\
\hline & \multirow{2}{*}{ Afluente } & \multicolumn{2}{|c|}{ Filtro 1} & \multicolumn{2}{|c|}{ Filtro 2} & \multicolumn{2}{|c|}{ Filtro 3} \\
\hline & & Efluente & Variação & Efluente & Variação & Efluente & Variação \\
\hline $\begin{array}{l}\text { Escherichia coli } \\
\text { (NMP/100mL) }\end{array}$ & 82 & 7 & $-91 \%$ & 18 & $-78 \%$ & 3 & $-96 \%$ \\
\hline Cor aparente (uH) & 48 & 42 & $-13 \%$ & 35 & $-27 \%$ & 38 & $-21 \%$ \\
\hline $\begin{array}{l}\text { Sólidos dissolvidos totais } \\
\text { (mg/L) }\end{array}$ & 118 & 31 & $-74 \%$ & 336 & $185 \%$ & 100 & $-15 \%$ \\
\hline $\begin{array}{l}\text { Sólidos dissolvidos fixos } \\
\text { (mg/L) }\end{array}$ & 24,0 & 14,0 & $-42 \%$ & 23,5 & $-2 \%$ & 22,0 & $-8 \%$ \\
\hline Turbidez (UT) & 6,4 & 3,2 & $-50 \%$ & 3,6 & $-44 \%$ & 3,4 & $-47 \%$ \\
\hline $\begin{array}{l}\text { Sólidos suspensos totais } \\
(\mathrm{mg} / \mathrm{L})\end{array}$ & 6,6 & 2,6 & $-61 \%$ & 2,8 & $-58 \%$ & 4,0 & $-39 \%$ \\
\hline $\begin{array}{l}\text { Sólidos dissolvidos } \\
\text { voláteis }(\mathrm{mg} / \mathrm{L})\end{array}$ & 92,0 & 18,3 & $-80 \%$ & 310,0 & $237 \%$ & 78,0 & $-15 \%$ \\
\hline $\begin{array}{l}\text { Sólidos suspensos fixos } \\
\text { (mg/L) }\end{array}$ & 0,8 & 0 & $-100 \%$ & 0 & $-100 \%$ & 0 & $-100 \%$ \\
\hline $\begin{array}{l}\text { Sólidos suspensos } \\
\text { voláteis (mg/L) }\end{array}$ & 5,8 & 2,6 & $-55 \%$ & 2,8 & $-52 \%$ & 4,0 & $-31 \%$ \\
\hline Sólidos totais $(\mathrm{mg} / \mathrm{L})$ & 120 & 31 & $-74 \%$ & 328 & $173 \%$ & 103 & $-14 \%$ \\
\hline $\begin{array}{l}\text { Sólidos totais fixos } \\
\text { (mg/L) }\end{array}$ & 25 & 14 & $-44 \%$ & 24 & $-4 \%$ & 22 & $-12 \%$ \\
\hline $\begin{array}{l}\text { Sólidos totais voláteis } \\
(\mathrm{mg} / \mathrm{L})\end{array}$ & 100 & 19 & $-81 \%$ & 312 & $212 \%$ & 81 & $-19 \%$ \\
\hline Temperatura $\left({ }^{\circ} \mathrm{C}\right)$ & 23,9 & 23,1 & $-3 \%$ & 22,8 & $-5 \%$ & 23,0 & $-4 \%$ \\
\hline $\mathrm{pH}$ & 6,20 & 6,44 & $3 \%$ & 6,52 & $5 \%$ & 6,16 & $-1 \%$ \\
\hline $\begin{array}{l}\text { Coliformes Totais } \\
\text { (NMP/100mL) }\end{array}$ & 6859 & 480 & $-93 \%$ & 2429 & $-65 \%$ & 462 & $-93 \%$ \\
\hline
\end{tabular}

Fonte: baseado em Nakada (2012).

Para cada experimento foram utilizadas cinco camadas de rede, para a combinação de filtros foram utilizadas três camadas de rede de náilon e duas camadas de rede metálica entrelaçadas e fixadas. A determinação de turbidez, demanda química de oxigênio e sólidos suspensos foi realizada de acordo com Ministry of Environmental Protection of the People's Republic of China (2006). Algumas características dos materiais utilizados como meios filtrantes podem ser observadas na Tabela 9.

De acordo com os resultados mostrados nas Tabelas 10 e 11 percebe-se que a remoção de poluentes nos filtros de náilon e de rede metálica foi muito similar. A rigidez do filtro metálico é muito maior que a do náilon, mas este enferruja ao longo do tempo. As redes combinadas obtiveram melhor desempenho como filtro, uma vez que o tamanho dos poros ficou menor por causa da sobreposição, retendo maior número de partículas.

Os parâmetros analisados por Wang et al. (2010) são insuficientes para validar a utilização dos meios filtrantes de rede de náilon e rede metálica para tratamento de água pluvial. Apesar da diminuição significativa da turbidez (59\%, 60\% e $77 \%$ ), o valor alcançado pelos efluentes nos três testes excede muito o padrão para usos não potáveis estabelecidos pela ABNT (2007). Observa-se que os autores propuseram o tratamento para o escoamento inicial, portanto provavelmente não estavam interessados em atingir padrões de qualidade elevados.

\section{Sistema autolimpante}

Vieira, Weeber e Ghisi (2013) analisaram a eficiência na remoção de partículas e na retrolavagem para três diferentes meios filtrantes, inseridos em um sistema de filtragem desenvolvido pelos próprios pesquisadores. O sistema foi criado a partir de componentes disponíveis no mercado brasileiro e idealizado de forma que não necessita utilizar energia elétrica, possui mecanismo autolimpante, é de fácil instalação, operação e manutenção, além de possuir baixo custo. 
Tabela 9 - Características das redes de náilon e rede metálica

\begin{tabular}{|c|c|c|c|c|}
\hline Filtro & Preço $\left(\$ / \mathbf{m}^{2}\right)$ & Poros $/ \mathrm{cm}^{2}$ & Tamanho do poro (mm) & Porosidade (\%) \\
\hline Náilon & 0,17 & 14 & 0,18 & 81 \\
\hline Metálica & 0,4 & 16 & 0,193 & 77 \\
\hline
\end{tabular}

Fonte: baseado em Wang et al. (2010).

\begin{tabular}{|c|c|c|c|c|c|c|}
\hline \multirow{2}{*}{ Parâmetro } & \multicolumn{3}{|c|}{ Rede de Náilon } & \multicolumn{3}{|c|}{ Rede Metálica } \\
\hline & Afluente & Efluente & Variação & Afluente & Efluente & Variação \\
\hline Turbidez (uT) & 97,8 & 40,3 & $-59 \%$ & 98,1 & 39,7 & $-60 \%$ \\
\hline Sólidos suspensos (mg/L) & 170,0 & 76,2 & $-55 \%$ & 167,0 & 80,0 & $-52 \%$ \\
\hline $\begin{array}{l}\text { Demanda química de } \\
\text { oxigênio }(\mathrm{mg} / \mathrm{L})\end{array}$ & 498,0 & 492,0 & $-1 \%$ & 503,0 & 496,0 & $-1 \%$ \\
\hline
\end{tabular}

Fonte: baseado em Wang et al. (2010)

Tabela 11 - Qualidade da água do afluente e filtrada pela combinação dos meios filtrantes de rede de náilon e rede metálica

\begin{tabular}{l|c|c|c}
\hline \multirow{2}{*}{ Parâmetro } & \multicolumn{3}{c}{ Rede de Náilon + Rede Metálica } \\
\cline { 2 - 4 } & Afluente & Efluente & Variação \\
\hline Turbidez (uT) & 95,5 & 21,7 & $-77 \%$ \\
Sólidos suspensos (mg/L) & 179,0 & 78,0 & $-56 \%$ \\
Demanda química de oxigênio (mg/L) & 505,0 & 492,9 & $-2 \%$ \\
\hline
\end{tabular}

Fonte: baseado em Wang et al. (2010).

O sistema, ilustrado na Figura 6, é baseado em filtragem de fluxo ascendente, enquanto a retrolavagem ocorre de forma descendente. Uma válvula magnética foi inserida para a realização da retrolavagem e funciona de forma automática, sendo acionada devido à pressão na coluna de água e fechada através de uma mola quando encerra o processo. Os três meios filtrantes possuíam área total de $60,8 \mathrm{~cm}^{2}$ e foram comprados no mercado local em Florianópolis, sendo um geotêxtil e dois tecidos filtrantes; suas características estão expostas na Tabela 12.

Uma mistura sintética com concentração de 1000 mg/L de água potável e fibra de trigo, com partículas de tamanho aleatório e turbidez de 70 NTU, foi utilizada nos experimentos. Optou-se por não utilizar água pluvial, que normalmente possui valores inferiores a 10 NTU, para serem conduzidos testes mais controlados. Foram coletadas amostras em triplicata no início e no final de cada ciclo de filtragem, além de uma única amostra intermediária. Os resultados dos testes estão expostos na Tabela 13.

O melhor resultado para a retrolavagem foi obtido pelo tecido filtrante 2, sendo capaz de reestabelecer toda a sua permeabilidade inicial através da remoção das partículas retidas. Os testes indicaram que, com a escolha adequada do meio filtrante, o sistema é capaz de realizar filtragem e autolimpeza adequadas. O sistema apresentou elevadas taxas de redução da turbidez, apesar de os valores não terem atingido o requerido pela ABNT (2007), o que pode ser consequência de ter-se optado pela utilização de um afluente com alta turbidez, incomum para água pluvial.

\section{Geotêxtil $1^{4}$}

Wang et al. (2010) analisaram o uso de geotêxtil como meio filtrante para remoção de poluentes no escoamento inicial. A análise foi feita no mesmo dispositivo descrito anteriormente na seção "Rede de Náilon e Rede Metálica”, na cidade de Pequim, e a determinação dos parâmetros foi realizada seguindo os mesmos padrões. De acordo com os autores, o geotêxtil é um excelente meio filtrante com características químicas e físicas perfeitas. Este material tem alta elasticidade, rigidez mecânica, porosidade e permeabilidade. Pode resistir a danos de materiais ácidos, alcalinos, de ultravioleta, mofo, ambientes úmidos e conter traças.

${ }^{4}$ Nomenclatura adotada pelos autores para diferenciação entre os materiais utilizados na pesquisa de Wang et al. (2010) e J ohor et al. (2017) 


\section{Figura 6 - Esquema representativo do sistema autolimpante}

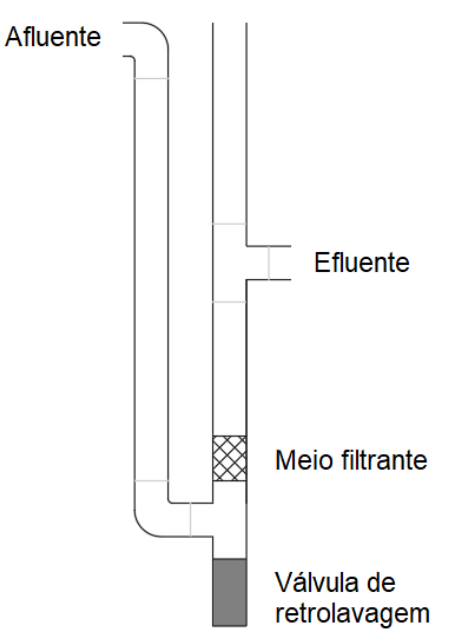

Fonte: baseado em Vieira, Weeber e Ghisi (2013).

Tabela 12 - Características dos meios filtrantes do sistema autolimpante

\begin{tabular}{l|c|c|c}
\hline \multirow{2}{*}{ Parâmetros } & \multicolumn{3}{|c}{ Meio Filtrante } \\
\cline { 2 - 4 } & Geotêxtil & Tecido Filtrante 1 & Tecido Filtrante 2 \\
\hline Tamanho de poro $(\mu \mathrm{m})$ & 130 & 75 & 75 \\
Espessura $(\mathrm{mm})$ & 3,60 & 0,53 & 1,07 \\
Peso específico $\left(\mathrm{g} / \mathrm{m}^{2}\right)$ & 600 & 320 & 490 \\
\hline
\end{tabular}

Fonte: baseado em Vieira, Weeber e Ghisi (2013).

Tabela 13 - Qualidade da água do afluente e filtrada pelo sistema autolimpante

\begin{tabular}{l|c|c|c|c|c|c|c}
\hline \multirow{2}{*}{ Parâmetro } & \multicolumn{7}{c}{ Sistema Autolimpante } \\
\cline { 2 - 8 } & \multirow{2}{*}{ Afluente } & \multicolumn{2}{|c}{ Geotêxtil } & Tecido Filtrante 1 & \multicolumn{2}{c}{ Tecido Filtrante 2 } \\
\cline { 2 - 8 } & & Efluente & Variação & Efluente & Variação & Efluente & Variação \\
\hline Turbidez (NTU) & 70 & 44 & $-63 \%$ & 46 & $-66 \%$ & 48 & $-68 \%$ \\
\hline
\end{tabular}

Fonte: baseado em Vieira, Weeber e Ghisi (2013).

O meio filtrante utilizado para tratar o escoamento inicial deve atender dois requisitos: capacidade de penetração e vida útil longa. O geotêxtil atende os dois. As características do material, que foi comprado no mercado local, podem ser observadas na Tabela 14 e um resumo dos resultados obtidos pode ser observado na Tabela 15.

A remoção de resíduos foi alta; apesar de os poros do geotêxtil serem pequenos, a sua porosidade é alta. Além disso, os poros absorvem a matéria orgânica. As características de absorção e filtragem juntas promovem elevado desempenho na remoção de poluentes. O geotêxtil é um material que está disponível com preço baixo e alta eficiência, então pode ser usado em muitos campos da engenharia. Contudo, o meio filtrante não atingiria os padrões de qualidade estabelecidos pela ABNT (2007) para turbidez.

\section{Geotêxtil 2}

Johor et al. (2017) analisaram o uso de geotêxtil como meio filtrante de sistemas de aproveitamento de água pluvial em áreas rurais. O foco do estudo foi a prevenção da proliferação de mosquitos que transmitem a dengue. As características do material estão descritas na Tabela 16.

O sistema é feito com tubos de PVC de $2^{\prime \prime} 1 / 2$, conforme representado na Figura 7. O design é baseado no estudo de Vieira, Weeber e Ghisi (2013), com a substituição da válvula magnética por uma manual. Alguns resultados experimentais estão mostrados na Tabela 17, obtidos pela média de doze resultados.

Os resultados de turbidez seguem os padrões de qualidade para usos não potáveis da ABNT (2007) mesmo antes da filtragem. A média de valores de pH atingiu valor adequado após a filtragem, porém, por meio da análise do desvio padrão, nem 
todas as amostras estão dentro dos limites. Temperatura e oxigênio dissolvido não são requisitos da norma. Além disso, o meio filtrante de geotêxtil mostrou-se adequado para a eliminação de larvas de mosquitos, que era o principal objetivo da pesquisa. Este sistema é barato, durável, fácil de montar e possui pouca manutenção (VIEIRA; WEEBER; GHISI, 2013).

\section{Escória de usina termoelétrica}

Wang et al. (2010) analisaram diferentes espessuras de camadas de escória de usinas termoelétricas como meio filtrante para remoção de poluentes da água de escoamento inicial. A análise foi feita no mesmo dispositivo descrito na seção "Rede de Náilon e Rede Metálica", na cidade de Pequim, e a determinação dos parâmetros foi realizada seguindo os mesmos padrões. Foram realizados três experimentos com diferentes espessuras da camada de escória. A escória foi adquirida no mercado local com densidade de $2,3 \mathrm{~g} / \mathrm{cm}^{3}$ e porosidade de $55 \%$.

Tabela 14 - Características do geotêxtil 1

Fonte: baseado em Wang et al. (2010).

\begin{tabular}{l|l}
\hline \multicolumn{2}{l}{ Características do geotêxtil 1 } \\
\hline Densidade & $200 \mathrm{~g} / \mathrm{m}^{2}$ \\
Espessura & $2,245 \mathrm{~mm}$ \\
Porosidade & $93,54 \%$ \\
Permeabilidade & $2,64 \mathrm{l} / \mathrm{s}$ \\
\hline
\end{tabular}

Tabela 15 - Qualidade da água do afluente e filtrada pelo geotêxtil 1

\begin{tabular}{l|c|c|c}
\hline \multicolumn{1}{c|}{ Parâmetro } & \multicolumn{3}{c}{ Geotêxtil 1 } \\
\cline { 2 - 4 } & Afluente & Efluente & Variação \\
\hline Turbidez (uT) & 96,5 & 19,9 & $-79 \%$ \\
Sólidos suspensos (mg/L) & 182,0 & 61,2 & $-66 \%$ \\
Demanda química de oxigênio (mg/L) & 507,0 & 432,0 & $-15 \%$ \\
\hline
\end{tabular}

Fonte: baseado em Wang et al. (2010).

Tabela 16 - Características do geotêxtil 2

\begin{tabular}{l|c}
\hline \multicolumn{2}{c}{ Características do geotêxtil 2} \\
\hline Densidade & $125 \mathrm{~g} / \mathrm{m}^{2}$ \\
Espessura & $0,9 \mathrm{~mm}$ \\
Permeabilidade & $115 \mathrm{l} / \mathrm{m}^{2} \mathrm{~s}$ \\
\hline
\end{tabular}

Fonte: baseado em J ohor et al. (2017).

Figura 7 - Esquema representativo do filtro de geotêxtil 2

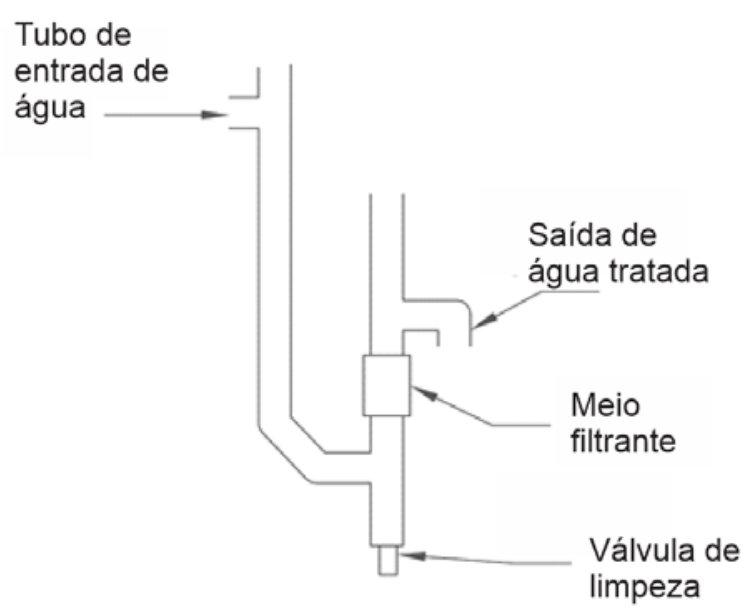

Fonte: baseado em J ohor et al. (2017). 
A grande quantidade de carbono contida na escória faz com que o material tenha ação semelhante à do carvão ativado, sendo capaz de absorver diversos poluentes do escoamento inicial, como matéria orgânica, metais pesados e sólidos suspensos. O alumínio presente na escória age como coagulante, aumentando a eficiência de filtragem. Um resumo dos resultados da pesquisa pode ser observado na Tabela 18.

Dentre os três filtros, o de espessura de $30 \mathrm{~cm}$ apresentou maior eficiência na taxa de remoção de todos os parâmetros, atingindo 89,2\% de redução de turbidez. No entanto, é necessário avaliar a viabilidade de uso do mesmo, uma vez que os valores de remoção ficaram muito próximos ao filtro de $20 \mathrm{~cm}$, sendo a maior diferença para a variação de demanda química de oxigênio, de 2,5 pontos percentuais a mais.

Wang et al. (2010) observaram que quanto mais espessa a camada de escória, mais caro o filtro custará e mais difícil será sua manutenção. Além disso, um filtro que usa este material pode entupir após certo tempo de uso. Os autores recomendam a escolha de uma espessura moderada devido aos problemas citados. Além disso, não foram analisados parâmetros suficientes para caracterizar esse meio filtrante como adequado, e nenhuma espessura de camada analisada atingiu os padrões da ABNT (2007) para turbidez.

\section{Filtro de areia revestido com hidróxido de ferro}

Ahammed e Meera (2006) analisaram a eficiência de um filtro de areia revestido com ferro no tratamento de água pluvial. A água foi coletada em um telhado de concreto e em outro de ferro galvanizado, ambos localizados em área residencial próxima a uma rodovia bastante movimentada. As amostras de água foram então armazenadas em garrafas plásticas, em um ambiente escuro a $4{ }^{\circ} \mathrm{C}$; antes de sua utilização nos testes, elas eram trazidas para temperatura ambiente e completamente misturadas. O meio filtrante foi preparado a partir de areia de rio passante na peneira de $800 \mu \mathrm{m}$ e retida na de $300 \mu \mathrm{m}$, que foi lavada e seca a $105^{\circ} \mathrm{C}$. Depois, através do método proposto por Lukasik et al. (1996), o hidróxido de ferro foi incorporado na areia.

A areia revestida com hidróxido de ferro foi montada em colunas de $15 \mathrm{~cm}$ por $2,5 \mathrm{~cm}$, com uma camada de lã de vidro no fundo para evitar a perda de material, e as amostras de água foram passadas pelo filtro pelo efeito da gravidade.

Tabela 17 - Qualidade da água do afluente e filtrada pelo filtro de geotêxtil 2

\begin{tabular}{l|c|c|c}
\hline \multicolumn{1}{c|}{ Parâmetro } & \multicolumn{3}{c}{ Geotêxtil 2 } \\
\cline { 2 - 4 } & Afluente & Efluente & Variação \\
\hline Temperatura $\left({ }^{\circ} \mathrm{C}\right)$ & $26,56 \pm 5,44$ & $28,14 \pm 5,30$ & $6 \%$ \\
$\mathrm{pH}$ & $5,76 \pm 2,40$ & $6,14 \pm 2,48$ & $7 \%$ \\
Turbidez (uT) & $1,46 \pm 1,21$ & $0,94 \pm 0,97$ & $-36 \%$ \\
Oxigênio dissolvido (DO) & $4,94 \pm 2,22$ & $5,47 \pm 2,40$ & $18 \%$ \\
\hline
\end{tabular}

Fonte: baseado em J ohor et al. (2017).

Tabela 18 - Qualidade da água do afluente e filtrada pela escória de usina termoelétrica para camadas de $10 \mathrm{~cm}$ e $20 \mathrm{~cm}$

\begin{tabular}{l|c|c|c|c|c|c|c|c|c}
\hline \multirow{2}{*}{ Parâmetro } & \multicolumn{9}{c}{ Escória de Usina Termelétrica } \\
\cline { 2 - 10 } & \multicolumn{3}{c|}{$\mathbf{1 0} \mathbf{~ c m}$} & \multicolumn{3}{c}{$\mathbf{2 0} \mathbf{~ c m}$} & \multicolumn{3}{c}{$\mathbf{3 0} \mathbf{~ c m}$} \\
\cline { 2 - 10 } & $\mathbf{A}$ & $\mathbf{E}$ & $\mathbf{V}$ & $\mathbf{A}$ & $\mathbf{E}$ & $\mathbf{V}$ & $\mathbf{A}$ & $\mathbf{E}$ & $\mathbf{V}$ \\
\hline Turbidez (uT) & 94,5 & 15,7 & $-83 \%$ & 95,7 & 12,6 & $-87 \%$ & 95,3 & 10,3 & $-89 \%$ \\
Sólidos suspensos (mg/L) & 185,0 & 59,0 & $-68 \%$ & 188,0 & 43,2 & $-77 \%$ & 186,0 & 42,8 & $-77 \%$ \\
Demanda química de & 510,0 & 429,9 & $-16 \%$ & 509,0 & 428,1 & $-16 \%$ & 510,0 & 416,2 & $-18 \%$ \\
oxigênio (mg/L) & 26,7 & 25,2 & $-6 \%$ & 26,7 & 25,1 & $-6 \%$ & 26,5 & 24,8 & $-6 \%$ \\
Nitrogênio (mg/L) & 18,4 & 16,6 & $-10 \%$ & 18,7 & 16,2 & $-13 \%$ & 18,5 & 16,0 & $-14 \%$ \\
Fosfato (mg/L) &
\end{tabular}

Fonte: baseado em Wang et al. (2010).

Legenda:

$$
\begin{aligned}
& A=\text { Afluente; } \\
& E=\text { Efluente; e } \\
& V=\text { Variação. }
\end{aligned}
$$


O telhado de ferro galvanizado foi implementado para analisar a remoção simultânea de chumbo e zinco, além de coliformes fecais e totais. Os testes no telhado de concreto avaliaram a turbidez e a quantidade de bactérias através das medidas de coliformes totais, coliformes fecais e contagem de bactérias heterotróficas. Os resultados dos testes estão expostos na Tabela 19 para os telhados de concreto e de ferro galvanizado. Foram realizados outros testes variando o $\mathrm{pH}$ entre 6,0 e 9,0; constatou-se que esta mudança não afetou a remoção de bactérias.

O estudo mostrou eficiência de aproximadamente $97 \%$ na remoção de coliformes para ambos os sistemas. Comparando-se os testes utilizando a água coletada em telhado de ferro galvanizado e de concreto, constatou-se que, apesar de a primeira conter grandes quantidades de metais pesados, não ocorreram diferenças significativas na remoção de coliformes totais e coliformes fecais. Além disso, não foram detectados vazamentos de ferro da areia, visto que sua quantidade permaneceu inferior a 0,1 $\mathrm{mg} / \mathrm{L}$.

O filtro mostrou-se eficiente para remover simultaneamente bactérias e metais pesados com quantidades de zinco e chumbo atingindo valores menores que a recomendação da OMS para o consumo humano de água. Para turbidez, as amostras antes e depois da filtragem respeitaram o valor definido pela ABNT (2007) para usos restritivos; apesar de o sistema ter atingido pequenos valores e altas taxas de remoção para coliformes totais e fecais, estes parâmetros não satisfizeram o exigido por esta norma.

\section{Filtro com dois meios filtrantes}

Visando melhor desempenho para o tratamento de águas contaminadas por diversos poluentes, Ahammed e Meera (2010) elaboraram um sistema composto por filtros de areia revestida com óxido de manganês e areia revestida de óxido de ferro. Esta união dos dois meios filtrantes justifica-se pelo fato que o manganês é mais eficiente para a eliminação de metais pesados, enquanto o ferro, de micro-organismos. Dessa forma, agem em conjunto e resultam em melhor tratamento da água.

O meio filtrante foi preparado a partir de areia de rio passante na peneira de $800 \mu \mathrm{m}$ e retida na de $300 \mu \mathrm{m}$, que foi lavada e seca a $105^{\circ} \mathrm{C}$. Hidróxidos de ferro e manganês foram incorporados à areia através do método proposto por Liu et al. (2001).

O filtro foi montado em um cilindro de $2,5 \mathrm{~cm}$ de diâmetro, com uma camada de 7,5cm de espessura de areia revestida com óxido de manganês acima de uma camada de $7,5 \mathrm{~cm}$ de areia revestida de óxido de ferro. As amostras de água foram armazenadas e seus parâmetros de qualidade foram monitorados da mesma forma como descrito na seção "Filtro de Areia Revestido com Hidróxido de Ferro”.

A água pluvial foi coletada em um telhado de ferro galvanizado durante um evento de chuva completo e não passou por nenhum tratamento de first flush. Suas características, antes e após a filtragem, assim como a redução percentual dos parâmetros, são apresentadas na Tabela 20, com o valor médio entre as cinco amostras coletadas mais ou menos o desvio padrão. Coliformes fecais não foram monitorados, pois sua quantidade no afluente era muito pequena e sua eliminação total esperada.

\section{Tabela 19 - Qualidade da água do afluente e filtrada pelo filtro de areia revestido com hidróxido de} ferro

\begin{tabular}{l|c|c|c|c|c|c}
\hline \multirow{2}{*}{ Parâmetro } & \multicolumn{5}{c}{ Filtro de Areia Revestido com Hidróxido de Ferro } \\
\cline { 2 - 7 } & \multicolumn{2}{|c}{ Telhado de Concreto } & \multicolumn{2}{c}{ Telhado de Ferro Galvanizado } \\
\cline { 2 - 7 } & Afluente & Efluente & Variação & Afluente & Efluente & Variação \\
\hline $\begin{array}{l}\text { Coliformes totais } \\
\text { (MPN/100mL) }\end{array}$ & $1700 \pm 420$ & 27 & $-98 \%$ & $300 \pm 65$ & 10,5 & $-97 \%$ \\
$\begin{array}{l}\text { Coliformes fecais } \\
\text { (MPN/100mL) }\end{array}$ & $170 \pm 27$ & 3 & $-98 \%$ & $14 \pm 6$ & 3 & $-79 \%$ \\
$\begin{array}{l}\text { Contagem de placas } \\
\text { heterotróficas (CFU/mL) }\end{array}$ & $3500 \pm 600$ & 150 & $-96 \%$ & - & - & - \\
Turbidez (uT) & 8,2 & 1,15 & $-86 \%$ & - & - & - \\
pH & 6,5 & - & - & - & - & - \\
Chumbo (mg/L) & - & - & - & 0,11 & 0,01 & $-91 \%$ \\
Zinco (mg/L) & - & - & - & 3,6 & 0,1 & $-97 \%$ \\
\hline
\end{tabular}

Fonte: baseado em Ahammed e Meera (2006). 
Tabela 20 - Qualidade da água do afluente e filtrada pelo filtro com dois meios filtrantes

\begin{tabular}{l|c|c|c}
\hline \multicolumn{1}{c}{ Parâmetro } & \multicolumn{3}{c}{ Filtro com Dois Meios Filtrantes } \\
\cline { 2 - 4 } & Afluente & Efluente & Variação \\
\hline Coliformes totais (MPN/100mL) & $310 \pm 44$ & $3 \pm 2$ & $-99 \%$ \\
Coliformes fecais (MPN/100mL) & $17 \pm 6$ & - & - \\
Contagem de placas heterotróficas (CFU/mL) & $1300 \pm 345$ & $170 \pm 20$ & $-87 \%$ \\
Turbidez (uT) & $2,8 \pm 0,4$ & $1 \pm 0,1$ & $-64 \%$ \\
pH & $6,6 \pm 0,2$ & $6,9 \pm 0,1$ & $4 \%$ \\
Chumbo (mg/L) & $0,14 \pm 0,02$ & 0,01 & $-93 \%$ \\
Zinco (mg/L) & $2,20 \pm 0,34$ & $0,06 \pm 0,01$ & $-97 \%$ \\
\hline
\end{tabular}

Fonte: baseado em Ahammed e Meera (2010).

Foram também monitoradas as quantidades de manganês e ferro nos efluentes, constando-se que não houve transferência de tais compostos do filtro para a água e que suas concentrações se enquadram nos parâmetros de água para consumo humano. Apesar de o sistema não atingir 100\% de remoção de coliformes, o efluente se enquadra na categoria de água de baixo risco. A turbidez e o pH satisfazem os requisitos da ABNT (2007).

\section{Cestas escavadas e filtro de cartucho}

Drapper e Hornbuckle (2015) analisaram a efetividade de um filtro de cesta escavada, criado para filtrar os poluentes e sedimentos grosseiros. $\mathrm{O}$ método aplicado nesse estudo foi desenvolvido pela Queensland University of Technology, de acordo com Auckland Regional Council Proprietary Device Evaluation Protocol e o United States Urban Stormwater BMP Performance Monitoring Manual com algumas alterações para se adequar às condições locais da cidade de Ormiston, Queensland. Foram analisados nove eventos de chuva que atenderam ao protocolo, em um período de dezoito meses.

O sistema, ilustrado na Figura 8, foi instalado em uma área residencial urbana e inclui tanques para armazenamento de água vinda dos telhados, cestas escavadas, com formato quadrado e $900 \mathrm{~mm}$ de lado envolvidos por uma malha de $200 \mu \mathrm{m}$, e uma cova subterrânea com $850 \mathrm{~mm}$ de profundidade. A água que escoa pela superfície do piso e é levada ao sistema de tubulação através das cestas e a água que vêm do telhado entra no sistema abaixo das cestas.

A água, então, passa pelo filtro de cartucho, que utiliza perlita, zeolito e alumínio ativado para promover a filtração e absorção dos poluentes e nutrientes. A Tabela 21 mostra a média de remoção de poluentes obtida neste sistema.

Na maioria dos eventos, a concentração de sólidos totais na saída do sistema estava abaixo do limite de detecção ( $<5 \mathrm{mg} / \mathrm{L})$. A concentração de fósforo também ficou bem perto dos limites de detecção. A performance do sistema cumpriu os padrões de qualidade e atingiu $80 \%$ da remoção de sólidos suspensos, $60 \%$ do fósforo e $45 \%$ do nitrogênio. Não foram analisados os parâmetros considerados pela ABNT (2007), impossibilitando a comparação desse sistema com as normas brasileiras.

\section{Biofiltração}

Sistemas de filtragem incluindo um componente vegetal são geralmente chamados de "instalações de biorretenção”. Barrett, Limouzin e Lawler (2013) analisaram este tipo de sistema, com um total de doze colunas com combinações entre três meios filtrantes e duas espécies de plantas comumente encontradas no Texas. Os três meios filtrantes empregados foram areia de concreto, areia de alvenaria e uma variação do especificado pela cidade de Austin para biofiltração, que não utiliza húmus: suas características estão expostas na Tabela 22. Os dois tipos de plantas utilizadas foram Buffalograss 609 e Big Muhly, sendo seus nomes científicos, respectivamente, Buchloe dactyloides e Muhlenbergia lindheimeri.

As colunas foram montadas com diâmetro aproximado de $200 \mathrm{~mm}$, espessura do meio filtrante de $460 \mathrm{~mm}$ e uma camada de $150 \mathrm{~mm}$ de rochas de rio lavadas, com estes dois últimos separados por um tecido geotêxtil. No topo da coluna, um cano de acrílico de $410 \mathrm{~mm}$ foi colocado para reter a água durante os testes enquanto permitia que as plantas ali instaladas recebessem luz solar. As plantas foram então colocadas na coluna, sendo a Buffalograss 609 cultivada no próprio sistema e a Big Muhly em um recipiente para posteriormente ser transferida para a coluna, sendo o substrato na qual foi plantada removido quase completamente antes de seu uso.

Esperou-se um período de aproximadamente dois meses para as plantas se acomodarem antes de os testes serem iniciados. Também optou-se por incluir ou não uma zona submersa com uma fonte 
de carbono, sendo esta composta por pedaços de casca de madeira, através da elevação da saída em $150 \mathrm{~mm}$, a fim de analisar sua influência na remoção de óxidos de nitrogênio. Um esquema do sistema está ilustrado na Figura 9 e os diferentes tipos de colunas obtidas com combinações entre os componentes utilizados estão expostos na Tabela 23.

\section{Figura 8 - Esquema representativo do filtro de cestas escavadas e de cartucho}

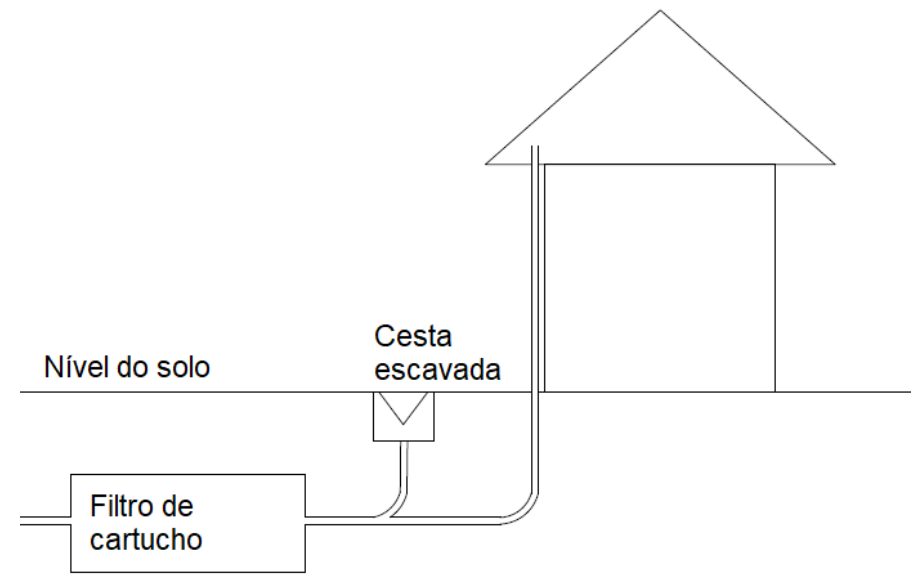

Fonte: baseado em Drapper e Hornbuckle (2015).

Tabela 21 - Qualidade da água do afluente e filtrada pelo filtro de cestas escavadas e de cartucho

\begin{tabular}{lcccccc}
\hline & \multicolumn{3}{c}{ Cestas Escavadas } & \multicolumn{3}{c}{ Filtro de Cartucho } \\
\cline { 2 - 7 } & Afluente & Efluente & Variação & Afluente & Efluente & Variação \\
\hline Sólidos suspensos (mg/L) & 102,19 & 69,75 & $-31,7 \%$ & 24,70 & 3,67 & $-85,1 \%$ \\
Nitrogênio (mg/L) & 1,18 & 0,74 & $-37,3 \%$ & 0,45 & 0,26 & $-42,2 \%$ \\
Fósforo total (mg/L) & 0,18 & 0,11 & $-38,9 \%$ & 0,04 & 0,02 & $-50,0 \%$ \\
\hline
\end{tabular}

Fonte: baseado em Drapper e Hornbuckle (2015).

\section{Tabela 22 - Características dos meios filtrantes para biofiltração}

\begin{tabular}{lcccc}
\hline \multicolumn{1}{c}{ Meio Filtrante } & Areia (\%) & Silte (\%) & Argila (\%) & Matéria orgânica (\%) \\
\hline Areia de concreto & 88 & 10 & 2 & 0,1 \\
Areia de alvenaria & 94 & 2 & 4 & 0,1 \\
Variação sem húmus & 73 & 18 & 9 & 0,4 \\
\hline
\end{tabular}

Fonte: baseado em Barrett, Limouzin e Lawler (2013).

\section{Figura 9 - Esquema representativo do sistema de biofiltração}

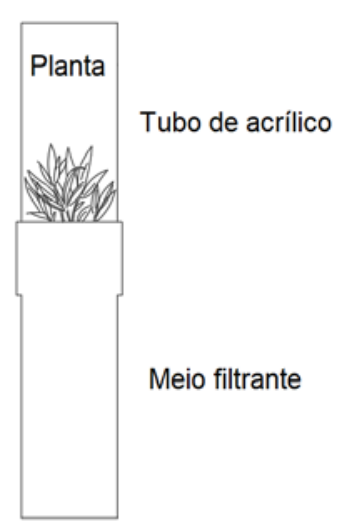

Fonte: baseado em Barrett, Limouzin e Lawler (2013). 
Tabela 23 - Diferentes sistemas de biofiltração montados

\begin{tabular}{c|c|c|c}
\hline \multirow{2}{*}{ Sistema } & \multicolumn{3}{|c}{ Características } \\
\cline { 2 - 4 } & Meio filtrante & Planta & Zona submersa \\
\hline 1 & Areia de concreto & nenhuma & ausente \\
2 & Areia de concreto & nenhuma & presente \\
3 & Areia de alvenaria & nenhuma & ausente \\
4 & Areia de alvenaria & Buffalo 609 & ausente \\
5 & Areia de alvenaria & Buffalo 609 & presente \\
6 & Areia de alvenaria & Big Muhly & ausente \\
7 & Areia de alvenaria & Big Muhly & presente \\
8 & Variação sem húmus & nenhuma & ausente \\
9 & Variação sem húmus & Buffalo 609 & ausente \\
10 & Variação sem húmus & Buffalo 609 & presente \\
11 & Variação sem húmus & Big Muhly & ausente \\
12 & Variação sem húmus & Big Muhly & presente \\
\hline
\end{tabular}

Fonte: baseado em Barrett, Limouzin e Lawler (2013).

A água pluvial foi coletada de uma rua residencial em Austin durante um evento de chuva de $18 \mathrm{~mm}$; a amostra foi então guardada por três dias a $4^{\circ} \mathrm{C}$ antes de ser utilizada. A água que passava pelas colunas era coletada em um grande recipiente e, quando este processo encerrava, o que levava algumas horas, era misturada e então uma amostra era retirada para análise. A eficiência na redução dos parâmetros é mostrada na Tabela 24.

O meio filtrante e a presença e o tipo de vegetação não tiveram grande influência na remoção de sólidos suspensos, porém colunas com vegetação apresentaram maior remoção de nitrogênio, sendo que aquelas com Big Muhly tiveram melhor desempenho que as com Buffalograss 609. Para a remoção de fósforo, pode-se notar que as colunas com plantas obtiveram melhores resultados, sem grandes diferenças entre as duas espécies analisadas; os sistemas com areia de concreto obtiveram menor eficiência que os outros meios filtrantes sem plantas. A presença de zona saturada aumentou significativamente a porcentagem de remoção de fósforo. Para os coliformes, a vegetação e a zona saturada aparentemente não tiveram influência em sua remoção e, apesar de os sistemas 8, 9, 10 e 12 terem obtido elevadas taxas de remoção, os valores não atingiram o exigido pela ABNT (2007).

Diversos outros testes utilizando simulação de precipitação pluviométrica foram feitos para se obter mais resultados e analisar o funcionamento das colunas ao longo do seu tempo de uso. Assim, foi constatado que a permeabilidade dos filtros sofreu redução no início e posteriormente se estabilizou. Durante o experimento, pôde-se verificar que a remoção permaneceu consistente durante o tempo para todas as colunas e nenhuma entupiu completamente, sendo que o meio filtrante com variação sem húmus obteve as menores taxas de condutividade hidráulica, o que pode ser justificado pelo seu menor tamanho de grão.

\section{Telhado verde}

A construção de telhados verdes, além de auxiliar nas condições térmicas das edificações, pode ser integrada com um sistema de aproveitamento de água pluvial, agindo como um local de coleta de água e removendo poluentes atmosféricos. Com este objetivo, Monteiro et al. (2016) criaram um sistema de telhado verde na cidade de Porto, Portugal, e monitoraram a qualidade da água coletada durante doze meses, o que abrangeu diferentes condições climáticas e níveis de precipitação.

O sistema, com $0,5 \mathrm{~m}^{2}$, foi montado conforme a Figura 10, seguindo um modelo de telhado verde extensivo, com espessura de substrato de $10 \mathrm{~cm}$. Foi utilizada argila expandida como uma camada para retenção de água e, para a camada de crescimento, uma mistura de argila expandida e matéria orgânica. Optou-se por utilizar argila expandida devido ao seu baixo peso e grande capacidade de reter água. Foram utilizadas três espécies de plantas aromáticas, sendo elas Satureja montana, Thymus pseudolanuginosus e Thymus caespititius, que foram inicialmente cultivadas de forma orgânica e depois introduzidas no sistema.

Esta escolha se deve a tolerância climática, baixa necessidade de manutenção, resistência à seca e pequena necessidade de água destas espécies. Inspeção mensal era realizada para verificar crescimento da vegetação e remoção de ervas daninhas. 
Tabela 24 - Variação percentual dos parâmetros analisados pelos sistemas de biofiltração

\begin{tabular}{|c|c|c|c|c|c|}
\hline \multirow[b]{2}{*}{ Sistema } & \multicolumn{5}{|c|}{ Variação em relação ao afluente (\%) } \\
\hline & $\begin{array}{c}\text { Escherichia } \\
\text { coli }\end{array}$ & $\begin{array}{c}\text { Coliformes } \\
\text { fecais }\end{array}$ & $\begin{array}{c}\text { Sólidos } \\
\text { suspensos }\end{array}$ & $\begin{array}{c}\text { Nitrogênio } \\
\text { total }\end{array}$ & $\begin{array}{c}\text { Fósforo } \\
\text { total }\end{array}$ \\
\hline Afluente & $\begin{array}{c}23600 \\
\mathrm{MPN} / 100 \mathrm{~mL}\end{array}$ & $\begin{array}{c}30200 \\
\text { CFU/100 mL }\end{array}$ & $336 \mathrm{mg} / \mathrm{L}$ & 9,77 mg/L & $1,57 \mathrm{mg} / \mathrm{L}$ \\
\hline 1 & $-97 \%$ & $-92 \%$ & $-90 \%$ & $-45 \%$ & $-70 \%$ \\
\hline 2 & $-98 \%$ & $-97 \%$ & $-96 \%$ & $-51 \%$ & $-73 \%$ \\
\hline 3 & $-92 \%$ & $-62 \%$ & $-93 \%$ & $-54 \%$ & $-72 \%$ \\
\hline 4 & $-94 \%$ & $-70 \%$ & $-91 \%$ & $-90 \%$ & $-83 \%$ \\
\hline 5 & $-98 \%$ & $-85 \%$ & $-96 \%$ & $-89 \%$ & $-89 \%$ \\
\hline 6 & $-93 \%$ & $-56 \%$ & $-94 \%$ & $-87 \%$ & $-85 \%$ \\
\hline 7 & $-99,03 \%$ & $-97 \%$ & $-97 \%$ & $-89 \%$ & $-98 \%$ \\
\hline 8 & $-99,94 \%$ & $-99,01 \%$ & $-91 \%$ & $-39 \%$ & $-69 \%$ \\
\hline 9 & $-99,67 \%$ & $-99,93 \%$ & $-95 \%$ & $-84 \%$ & $-90 \%$ \\
\hline 10 & $-99,97 \%$ & $-99,67 \%$ & $-94 \%$ & $-67 \%$ & $-91 \%$ \\
\hline 11 & $-94 \%$ & $-62 \%$ & $-94 \%$ & $-90 \%$ & $-88 \%$ \\
\hline 12 & $-99,47 \%$ & $-99 \%$ & $-96 \%$ & $-93 \%$ & $-96 \%$ \\
\hline
\end{tabular}

Fonte: baseado em Barrett, Limouzin e Lawler (2013).

Figura 10 - Esquema representativo do sistema de telhado verde

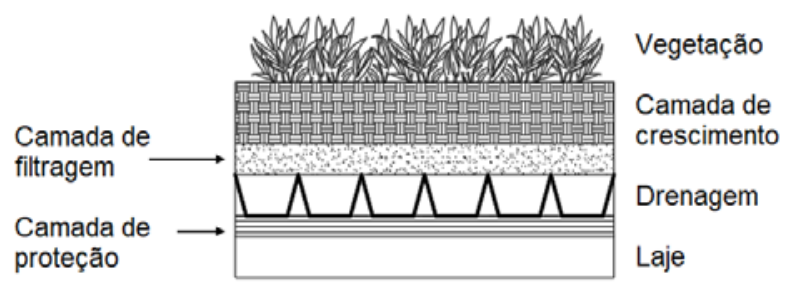

Fonte: Monteiro et al. (2016).

As amostras de água eram compostas do total de água acumulada em 24 horas e foram escolhidas aleatoriamente para múltiplos eventos de chuva; algumas continham água de first flush, o que afeta sua qualidade. A análise dos parâmetros foi realizada somente após a passagem da água pelo sistema, não sendo possível determinar a eficiência da filtragem no tratamento. Os testes para determinar a concentração de fósforo, amônia e nitrato foram realizados imediatamente após a coleta das amostras. A Tabela 25 mostra os valores médios obtidos durante o estudo.

Os níveis de demanda química de oxigênio geralmente estavam abaixo do limite de detecção. O estudo indicou que a água deste sistema pode ser utilizada para irrigação, descarga de vasos sanitários ou limpeza de pavimentos. As plantas utilizadas se mostraram adequadas para este tipo de utilização, visto que suportaram as condições de operação. Os valores médios de turbidez obtidos satisfizeram o exigido pela ABNT (2007) para usos restritivos e, considerando o desvio padrão, as amostras estavam dentro do estabelecido para usos menos restritivos.

\section{Telhado verde com filtro de membrana}

Teixeira et al. (2017) também analisaram a qualidade de água pluvial após passagem por um telhado verde, porém acompanhado por um filtro de membrana. A residência estudada está localizada na zona urbana do município de Curitiba - PR. Nesse sistema, água passa pelo telhado verde, que é composto por uma camada de $15 \mathrm{~cm}$ de terra, $5 \mathrm{~cm}$ de argila expandida para drenagem e uma manta geotêxtil como camada filtrante. Depois, ela é conduzida por canos de PVC até chegar ao reservatório inferior, de concreto, e ser bombeada para o reservatório superior, após passagem por dois filtros de membrana instalados em série, de $200 \mu \mathrm{m}$ e $50 \mu \mathrm{m}$, respectivamente. A vegetação utilizada na cobertura é grama. Todas as análises foram realizadas de acordo com procedimentos descritos em American Public Health Association (2005), em triplicata. Os parâmetros dos afluentes e efluentes do telhado verde e dos filtros de membrana estão apresentados na Tabela 26. 
Conforme observado pelos autores, a qualidade da água pluvial após percolação no telhado verde pode melhorar com relação a alguns parâmetros, mas também pode piorar com relação a outros. A água do telhado verde tratada com o filtro de membrana não atingiu os parâmetros necessários da ABNT (2007) para usos não potáveis. Porém, os usuários dos sistemas se mostram satisfeitos com a sua utilização. Os altos níveis de fosfato apresentados pela água podem ser oriundos do solo utilizado na cobertura.

Os autores apontam que para completo atendimento às normas da $\mathrm{ABNT}$, seria necessário acrescentar um sistema de desinfecção e sugerem que essa necessidade pode inibir os usuários de adquirir um sistema de aproveitamento de água pluvial.

\section{Pavimentos porosos com asfalto modificado}

Antunes, Thives e Ghisi (2016) apresentaram a primeira análise brasileira de aproveitamento de água pluvial através do tratamento com pavimentos porosos. Para isso, foi considerado o uso para fins não potáveis, como descarga, limpeza de ambientes externos e rega de jardins. O estudo foi desenvolvido levando em conta edificações de diferentes setores (residencial, público e comercial) na cidade de Florianópolis - SC.

Para a análise do meio filtrante, considerou-se somente a superfície de concreto asfáltico de pavimentos porosos, sendo desenvolvidos quatro modelos com diferentes placas de asfalto modificado. Como as misturas porosas de asfalto apresentam grande quantidade de espaço vazio, elas são normalmente mais susceptíveis à degradação quando comparadas com misturas mais densas. Para avaliar a resistência à degradação, algumas placas foram expostas a um processo cíclico na água. A Tabela 27 apresenta as placas e o modificador utilizado em cada uma delas.

Os modelos criados foram expostos a eventos de precipitação, permitindo a infiltração de água pluvial pelos mesmos, tornando possível a análise da água pluvial antes e após a passagem pelo meio filtrante. Para isso, as placas de asfalto poroso foram posicionadas sobre caixas de acrílico. A coleta da água pluvial foi feita diretamente pela exposição de uma caixa de acrílico ao lado dos modelos criados. Além disso, amostras de escoamento superficial em uma estrada local foram coletadas para avaliar sua qualidade.

Tabela 25 - Qualidade da água filtrada pelo sistema de telhado verde

\begin{tabular}{ll}
\hline \multicolumn{1}{c}{ Parâmetro } & Resultado \\
\hline Turbidez (NTU) & $9,81 \pm 3,09$ \\
$\mathrm{pH}$ & $7,55 \pm 0,26$ \\
Condutividade térmica $(\mu \mathrm{S} / \mathrm{cm})$ & $147 \pm 55$ \\
Fósforo (mg P/L) & $1,46 \pm 0,17$ \\
Amônia (mg N/L) & $0,11 \pm 0,14$ \\
Nitrato (mg N/L) & $1,35 \pm 1,03$ \\
\hline
\end{tabular}

Fonte: Monteiro et al. (2016).

Tabela 26 - Qualidade da água do afluente e após passar pelo telhado verde e pelo filtro de membrana

\begin{tabular}{l|c|c|c|c|c|c}
\hline \multirow{2}{*}{ Parâmetro } & \multicolumn{3}{c}{ Telhado Verde } & \multicolumn{3}{c}{ Filtro de Membrana } \\
\cline { 2 - 7 } & Afluente & Efluente & Variação & Afluente & Efluente & Variação \\
\hline Coliformes totais & $1,1-$ & $0,0-$ & & $0,0-$ & $<18,0-$ & - \\
(NMP/100) & 23,0 & $30.000,0$ & - & $30.000,0$ & $7.900,0$ & - \\
Escherichia coli (NMP/100) & $1,1-$ & $0,0-280,0$ & - & $0,0-280,0$ & $0,0-45,0$ & $-2 \%$ \\
Temperatura ( $\left.{ }^{\circ} \mathrm{C}\right)$ & 18,0 & & & 16,38 & 16,13 & $-2 \%$ \\
Turbidez (UNT) & 16,38 & 16,38 & $0 \%$ & 9,86 & 3,18 & $-68 \%$ \\
pH & 7,08 & 9,86 & $39 \%$ & 6,96 & $-1 \%$ & $-77 \%$ \\
Amônia (mg/L) & 5,81 & 6,96 & $20 \%$ & $0,96 \%$ & $-60 \%$ \\
Nitrito (mg/L) & 0,91 & 0,26 & $-71 \%$ & 0,26 & 0,06 & $-82 \%$ \\
Nitrato (mg/L) & 0,03 & 0,15 & $400 \%$ & 0,15 & 0,06 & $-56 \%$ \\
Fosfato (mg/L) & $<0,50$ & 2,90 & $480 \%$ & 2,90 & 0,51 & $14 \%$ \\
Oxigênio dissolvido (mg/L) & 6,57 & 14,90 & $127 \%$ & 14,90 & 10,99 & $-60 \%$ \\
Demanda química de & 9,73 & 9,64 & $-1 \%$ & 9,64 & 17,00 & $-60 \%$ \\
oxigênio (mg/L) & 21,43 & 42,57 & $99 \%$ & 42,57 & & \\
\hline
\end{tabular}

Fonte: baseado em Teixeira et al. (2017). 
Tabela 27 - Identificação das placas e o agente modificador utilizado

\begin{tabular}{c|l}
\hline Placa & \multicolumn{1}{|c}{ Agente modificador } \\
\hline 1 & Borracha de pneu sem processo cíclico na água \\
2 & Borracha de pneu com processo cíclico na água \\
3 & Polímero SBS (estireno-butadieno-estireno) sem processo cíclico na água \\
4 & Polímero SBS (estireno-butadieno-estireno) com processo cíclico na água \\
\hline
\end{tabular}

Fonte: baseado em Antunes, Thives e Ghisi (2016).

Os parâmetros avaliados foram alumínio, amônia, cobre, cromo, ferro, fósforo, nitrito, oxigênio dissolvido, pH e zinco. Os métodos de análise utilizados foram os definidos pelo fornecedor dos reagentes químicos. A qualidade da água pluvial antes e após a passagem no meio filtrante é apresentada na Tabela 28.

Como os parâmetros analisados diferem dos definidos pela ABNT (2007), não é possível concluir se a qualidade final da água foi satisfatória. No entanto, segundo os dados obtidos, percebe-se que a qualidade da água pluvial na cidade de Florianópolis exige tratamento para ser utilizada. Em relação aos meios filtrantes analisados, as placas de asfalto modificadas com polímero apresentaram as concentrações de amônia e fósforo mais elevadas. Para os outros parâmetros não ocorreram mudanças significativas. A qualidade da água coletada do escoamento superficial de uma estrada local asfaltada foi similar aos resultados encontrados na literatura.

\section{Filtro separador de sólidos}

Teixeira et al. (2017) analisaram a qualidade da água pluvial após passagem por um filtro separador de sólidos, que elimina sólidos maiores por um sistema de cascata e os menores pela passagem da água por uma malha em aço inox de $0,250 \times 0,600 \mathrm{~mm}$. O filtro é autolimpante e está disponível no mercado brasileiro. É indicado para usos residenciais, com área de contribuição de até $200 \mathrm{~m}^{2}$.

O sistema foi instalado na zona urbana do município de Curitiba - PR. A água pluvial passa por um telhado de telhas de concreto, é coletada por uma calha de zinco com pintura em esmalte sintético, passa pelo filtro e é armazenada em um reservatório de polietileno de alta densidade (Pead), de onde foi coletada a amostra de efluente.
Todas as análises foram realizadas de acordo com os procedimentos descritos em American Public Health Association (2005), em triplicata. Os parâmetros analisados correspondem àqueles exigidos pela ABNT (2007) para usos não potáveis e estão apresentados na Tabela 29.

Apesar do valor para turbidez ter atingido valores menores de 2 UNT, conforme exigido pela ABNT (2007), o valor definido em norma para os coliformes totais não foi atingido em nenhuma amostra. Os autores concluíram que, mesmo para usos menos restritivos, seria necessário um sistema de desinfecção para o completo atendimento à norma, contudo, ressaltam que os moradores da casa estão satisfeitos com o sistema.

\section{Síntese dos resultados}

Para avaliar a eficiência das diversas unidades de tratamento analisadas, compararam-se as taxas de variação obtidas em cada parâmetro conforme o sistema utilizado. Alguns parâmetros não foram considerados uma vez que não havia informações suficientes ou não possuíam relação direta com a qualidade da água.

A Tabela 30 apresenta uma compilação das maiores e menores taxas de variação por parâmetro exigido pela ABNT (2007). Para a qualidade de água definida por esta norma, somente o sistema de Membrana Metálica de $1 \mu \mathrm{m}$ com Ozonização atingiu o valor necessário para coliformes totais. Com relação a coliformes fecais, nenhum modelo obteve total remoção, apesar das altas taxas para Biofiltração 09 e 10. Para turbidez, os modelos de Membrana Metálica, Filtro de Areia Revestido com Hidróxido de Ferro e Filtro Separador de Sólidos atingiram o valor exigido, enquanto o Filtro de Pressão, Filtro com Dois Meios Filtrantes e a etapa do Filtro de Membrana para o sistema de Telhado Verde com Filtro de Membrana obtiveram valores absolutos adequados para usos menos restritivos. 
Tabela 28 - Qualidade da água do afluente e filtrada pelas placas de pavimentos porosos com asfalto modificado

\begin{tabular}{l|c|c|c|c|c|c|c|c|c}
\hline \multirow{2}{*}{ Parâmetro } & \multicolumn{10}{c}{ Pavimentos Porosos } \\
\cline { 2 - 10 } & \multirow{2}{*}{ Afluente } & \multicolumn{2}{|c|}{ Placa 1 } & \multicolumn{2}{c}{ Placa 2 } & \multicolumn{2}{c}{ Placa 3 } & \multicolumn{2}{c}{ Placa 4 } \\
\cline { 2 - 10 } & & $\mathbf{E}$ & $\mathbf{V}$ & $\mathbf{E}$ & $\mathbf{V}$ & $\mathbf{E}$ & $\mathbf{V}$ & $\mathbf{E}$ & $\mathbf{V}$ \\
\hline Amônia (mg/L) & 0,41 & 0,22 & $-46 \%$ & 0,20 & $-51 \%$ & 0,59 & $44 \%$ & 0,71 & $73 \%$ \\
Fósforo (mg/L) & 0,14 & 0,46 & $229 \%$ & 0,40 & $186 \%$ & 0,78 & $457 \%$ & 0,69 & $393 \%$ \\
Nitrito (mg/L) & 0 & 0,01 & - & 0,01 & - & 0,01 & - & 0,01 & - \\
Oxigênio dissolvido & 9,0 & 9,0 & $0 \%$ & 9,0 & $0 \%$ & 8,9 & $-1 \%$ & 8,9 & $-1 \%$ \\
(mg/L) & 5,4 & 5,5 & $2 \%$ & 5,8 & $7 \%$ & 5,8 & $7 \%$ & 5,6 & $4 \%$ \\
pH & & &
\end{tabular}

Fonte: baseado em Antunes, Thives e Ghisi (2016).

Legenda:

$E=$ Efluente; $\mathrm{e}$

$\mathrm{V}=$ Variação.

Tabela 29 - Qualidade da água do afluente e efluente após passagem pelo filtro separador de sólidos

\begin{tabular}{l|c|c|c}
\hline \multirow{2}{*}{ Parâmetro } & \multicolumn{3}{c}{ Filtro Separador de Sólidos } \\
\cline { 2 - 4 } & Afluente & Efluente & Variação \\
\hline Coliformes totais (NMP/100) & $1,1-23,0$ & $<18,0-4900,0$ & - \\
Escherichia coli (NMP/100) & $1,1-18,0$ & $0,0-<18,0$ & - \\
Temperatura $\left({ }^{\circ} \mathrm{C}\right)$ & 16,38 & 15,25 & $-7 \%$ \\
Turbidez (UNT) & 7,08 & 1,56 & $-78 \%$ \\
pH & 5,81 & 6,29 & $8 \%$ \\
Amônia (mg/L) & 0,91 & 0,12 & $-87 \%$ \\
Nitrito (mg/L) & 0,03 & $<0,01$ & $-67 \%$ \\
Nitrato (mg/L) & $<0,50$ & 0,73 & $46 \%$ \\
Fosfato (mg/L) & 6,57 & 7,39 & $12 \%$ \\
Oxigênio dissolvido (mg/L) & 9,73 & 9,46 & $-3 \%$ \\
Demanda química de oxigênio (mg/L) & 21,43 & 16,86 & $-21 \%$ \\
\hline
\end{tabular}

Fonte: baseado em Teixeira et al. (2017).

Para cor $^{5}$, somente o filtro de Membrana Metálica atingiu o valor exigido. Nota-se que, para estes dois últimos parâmetros, os sistemas que obtiveram as melhores taxas não alcançaram o valor exigido, indicando que a qualidade inicial da água tem grande influência no valor obtido para o efluente. Entre todas as unidades analisadas, somente o Geotêxtil 2, os Pavimentos Porosos com Asfalto Modificado e o Filtro Separador de Sólidos não mantiveram o pH dos efluentes dentro da faixa necessária.

O sistema que apresentou maior eficiência na remoção de coliformes fecais e Escherichia coli foi o de Biofiltração 10, enquanto para remoção de coliformes totais, foram os sistemas de Membrana Metálica com Ozonização e o de Íons de Prata. No entanto, houve grande variação dos resultados encontrados para o segundo modelo, variando a

${ }^{5} 0$ parâmetro definido pela ABNT (2007) é cor aparente. No entanto, nos artigos revisados, o parâmetro é definido como cor sendo necessário atentar para possíveis diferenças de significado. taxa de remoção de 0-100\%, não sendo confiável para uso no tratamento de água. As elevadas remoções desses parâmetros nos últimos dois sistemas citados se dá principalmente pela presença de um mecanismo que possibilita a desinfecção da água, sendo para o de Membrana Metálica com Ozonização o aerador de ozônio. Contudo, notou-se que outros modelos compostos somente por filtração mecânica também obtiveram resultados bastante elevados, sendo que a Membrana Metálica, o Filtro de Areia Revestido com Ferro, o Filtro com Dois Meios Filtrantes e o Filtro de Pressão obtiveram resultados superiores a $90 \%$.

Observou-se também grande diferença nas taxas de variação para turbidez entre os modelos, e que, para cor, estas se mantiveram bem baixas. Essa diferença entre o valor de turbidez e o valor de cor aparente indica que a quantidade de sólidos dissolvidos em águas pluviais é geralmente baixa. Para a turbidez, o sistema que apresentou maior taxa de remoção foi o sistema de Escória de Usina Termelétrica com $30 \mathrm{~cm}$ e, para o segundo, a maior 
redução foi do modelo F2 do Filtro de Pressão. Em alguns casos, como nas Membranas Metálicas, os valores absolutos do afluente para estes parâmetros encontravam-se muito baixos, o que pode ter influenciado no baixo valor da taxa de remoção obtida para os sistemas. Apesar das taxas de variação do $\mathrm{pH}$ se manterem baixas para todos os modelos, isso não revela muito sobre a eficiência do sistema em si, pois, para este parâmetro, o seu valor absoluto é mais importante que sua variação. Mesmo assim, a etapa do Telhado Verde para o sistema de Telhado Verde com Filtro de Membrana obteve a maior variação, neutralizando o pH, que inicialmente era baixo. Conforme citado por Teixeira et al. (2017), a alcalinização do pH em filtros com telhado verde já era esperada devido à estrutura do sistema (BERNDTSSON; EMILSSON; BENGTSSON; 2009). A Tabela 31 apresenta as maiores taxas de variação do $\mathrm{pH}$ obtidas e seu respectivo sistema de tratamento.

Com relação à redução da demanda química de oxigênio, os melhores resultados foram obtidos pela Membrana Metálica de $0,5 \mu \mathrm{m}$ e pela etapa do Filtro de Membrana do sistema Telhado Verde com Filtro de Membrana. Este último também obteve o melhor resultado para o aumento do oxigênio dissolvido. A redução da demanda química de oxigênio demonstrou sofrer maior influência com o uso de membranas com pequenos orifícios. O sistema de Biofiltração 12 obteve a maior taxa de redução para sólidos suspensos, nitrogênio e fosfato. Para a redução de nitrato e fosfato, a maior taxa foi obtida pela etapa do Filtro de Membrana do sistema de Telhado Verde com Filtro de Membrana, enquanto para nitrito e amônia foi obtida pelo Filtro Separador de Sólidos.

\section{Conclusão}

A falta de padronização dos métodos e parâmetros para avaliação dos filtros para aproveitamento de água pluvial dificulta a análise e definição daqueles que são adequados para a atividade. Identificou-se que houve grande variação nos parâmetros analisados, principalmente pelo fato das análises desenvolvidas visarem a remoção de parâmetros específicos conforme a demanda da região ou do tipo de material integrante em cada sistema. Além disso, é importante ressaltar que os métodos de dimensionamento utilizados para cada sistema são essenciais para sua eficiência. No entanto, a revisão realizada não abrangeu essa análise por falta dessa informação nos trabalhos analisados. Mesmo com a presença de poucos poluentes na água coletada, não é possível afirmar que alguma das unidades levantadas atingiu a qualidade exigida pela norma brasileira. Isso sugere que, para facilitar e incentivar o uso da água pluvial para fins não potáveis no Brasil, é necessário reavaliar e adequar as normas de forma criteriosa, e por meio de novos estudos encontrar parâmetros e exigências que condizem com a realidade desta aplicação.

Tabela 30 - Relação das maiores e menores taxas de redução dos parâmetros exigidos pela ABNT (2007)

\begin{tabular}{|c|c|c|c|c|c|c|c|c|}
\hline Parâmetro & \multicolumn{2}{|c|}{ Coliformes totais } & \multicolumn{2}{|c|}{ Coliformes fecais } & \multicolumn{2}{|c|}{ Turbidez } & \multicolumn{2}{|c|}{ Cor } \\
\hline Filtro & $\begin{array}{l}\text { Memb. } \\
\text { Metálica } \\
\text { com } \\
\text { Ozoniz. } \\
1 \mu \mathrm{m}\end{array}$ & $\begin{array}{l}\text { Íons de } \\
\text { Prata } \\
\text { Ionização } \\
\text { e } \\
\text { Filtragem }\end{array}$ & $\begin{array}{l}\text { Biofiltr. } \\
09\end{array}$ & $\begin{array}{l}\text { Biofiltr. } \\
06\end{array}$ & $\begin{array}{l}\text { Escória } \\
\text { de Usina } \\
\text { Term. } \\
30 \mathrm{~cm}\end{array}$ & $\begin{array}{l}\text { Memb. } \\
\text { Metálica } \\
5 \mu \mathrm{m}\end{array}$ & $\begin{array}{l}\text { Filtro } \\
\text { de } \\
\text { Pressão } \\
\text { F2 }\end{array}$ & $\begin{array}{l}\text { Memb. } \\
\text { Metálic } \\
\text { a } 5 \mu \mathrm{m} \\
\text { e } 1 \mu \mathrm{m}\end{array}$ \\
\hline Variação & $-100 \%$ & $\begin{array}{l}0 \% \text { até } \\
-100 \%\end{array}$ & $-99,93 \%$ & $-56 \%$ & $-89 \%$ & $-18 \%$ & $-27 \%$ & $-18 \%$ \\
\hline
\end{tabular}

Tabela 31 - Maiores taxas de variação obtidas para o pH

\begin{tabular}{|c|c|c|c|c|c|c|}
\hline \multirow[t]{2}{*}{ Filtro } & \multirow{2}{*}{\begin{tabular}{|c|} 
Filtro \\
Separador de \\
Sólidos
\end{tabular}} & \multirow{2}{*}{$\begin{array}{c}\text { Geotêxtil } \\
2\end{array}$} & \multirow{2}{*}{$\begin{array}{l}\text { Telhado Verde com } \\
\text { filtro de membrana }\end{array}$} & \multicolumn{2}{|c|}{$\begin{array}{c}\text { Pavimentos Porosos com } \\
\text { Asfalto Modificado } \\
\end{array}$} & \multirow{2}{*}{$\begin{array}{c}\text { Filtro } \\
\text { Separador } \\
\text { de Sólidos } \\
\end{array}$} \\
\hline & & & & Placa 2 & Placa 3 & \\
\hline Variação & $8 \%$ & $7 \%$ & $20 \%$ & $7 \%$ & $7 \%$ & $8 \%$ \\
\hline
\end{tabular}




\section{Referências}

ADLER, I.; HUDSON-EDWARDS, K. A.; CAMPOS, L. Converting Rain Into Drinking Water: quality issues and technological advances. Water Science \& Technology: Water Supply, v. 11, n. 6, p. 659-667, dez. 2011.

AHAMMED, M. M.; MEERA, V. Iron Hydroxide-Coated Sand Filter for Household Drinking Water From Roof-Harvested Rainwater. Journal of Water Supply: Research and Technology - AQUA, v. 55, n. 7-8, p. 493-498, nov. 2006.

AHAMMED, M. M.; MEERA, V. Metal Oxide/Hydroxide-Coated Dual-Media Filter for Simultaneous Removal of Bacteria and Heavy Metals From Natural Waters. Journal of Hazardous Materials, v. 181, n. 1-3, p. 788-793, set. 2010.

\section{AMERICAN PUBLIC HEALTH} ASSOCIATION. Standard Methods for the Examination of Water and Wastewater. 21. ed. Washington: APHA, 2005.

ANTUNES, L.; THIVES, L.; GHISI, E. Potential For Potable Water Savings in Buildings by Using Stormwater Harvested from Porous Pavements. Water, v. 8, n. 4, p. 110-128, 23 mar. 2016.

ASSOCIAÇÃO BRASILEIRA DE NORMAS TÉCNICAS. NBR 15527: água de chuva: aproveitamento de coberturas em áreas urbanas para fins não potáveis: requisitos. Rio de Janeiro, 2007.

BARRETT, M. E.; LIMOUZIN, M.; LAWLER, D. F. Effects of Media and Plant Selection on Biofiltration Performance. Journal of Environmental Engineering, v. 139, n. 4, p. 462470, abr. 2013.

BERNDTSSON, J. C.; EMILSSON, T.; BENGTSSON, L. The Influence of Extensive Vegetated Roofs on Runoff Quality. Science of the Total Environment, v. 355, n. 1/3, p. 48-63, 2009.

CAMPISANO, A.; MODICA, C. Optimal Sizing of Storage Tanks for Domestic Rainwater Harvesting in Sicily. Resources, Conservation and Recycling, v. 63, p. 9-16, jun. 2012.

DRAPPER, D.; HORNBUCKLE, A. Field Evaluation of a Stormwater Treatment Train with Pit Baskets and Filter Media Cartridges in Southeast Queensland. Water, v. 7, n. 8, p. 44964510, 17 ago. 2015.
JOHOR, S. F. W. et al. Filtration of Rainwater Harvesting System in Rural Area. Journal of Engineering Science and Technology, v. 12, n. 1, p. 181-191, abr. 2017.

KIM, R-H. et al. Advanced Treatment of Rainwater Using Metal Membrane Combined With Ozonation. In: INTERNATIONAL RAINWATER CATCHMENT SYSTEMS CONFERENCE, 11., Texcoco, 2003.

Proceedings... Texсосо: International Rainwater Catchment Systems Association, 2003.

KIM, R-H. et al. Reuse of Greywater and Rainwater Using Fiber Filter Media and Metal Membrane. Desalination, v. 202, n. 1-3, p. 326332, jan. 2007.

KIM, R-H.; LEE, S.; KIM, J-O. Application of a Metal Membrane for Rainwater Utilization: filtration characteristics and membrane fouling. Desalination, v. 177, n. 1-3, p. 121-132, jun. 2005.

KIM, R-H.; LEE, S.; KIM, Y-K. Rainwater Treatment Process for Building Drainage Using Fiber Filter Media. In: INTERNATIONAL RAINWATER CATCHMENT SYSTEMS CONFERENCE, 11., Texсосо, 2003.

Proceedings... Texсосо: International Rainwater Catchment Systems Association, 2003.

KWAADSTENIET, M. et al. Domestic Rainwater Harvesting: Microbial and chemical water quality and point-of-use treatment systems. Water, Air, \& Soil Pollution, v. 224, n. 7, p. 1-19, jun. 2013.

LANDAGE, S. M.; WASIF, A. I.; SAPKAL, P. P. Studies of Nonwoven Fabrics For Water Filtration. International Journal of advanced Research in Management and Social Sciences, v. 2, n. 7, p. 182-194, jul. 2013.

LIU, D. et al. Surface Characteristics of SorptiveFiltration Storm Water Media. I: low-density $\left(\rho_{\mathrm{s}}<\right.$ 1.0) oxide-coated buoyant media. Journal of Environmental Engineering, v. 127, n. 10, p. 868-878, out. 2001.

LUKASIK, J. et al. Adsorption of Microorganisms to Sand Diatomaceous Earth Particles Coated With Metallic Hydroxides. Kona Powder and Particle Journal, v. 14, n. 1, p. 87-91, 1996.

MINISTRY OF ENVIRONMENTAL PROTECTION OF THE PEOPLE'S REPUBLIC OF CHINA. Standard Methods for the Examination of Water and Wastewater. 4. ed. Beijing: MEP, 2006.

MONTEIRO, C. M. et al. Contributions to the Design of Rainwater Harvesting Systems in Buildings with Green Roofs in a Mediterranean Climate. Water Science And Technology, v. 73, n. 8, p. 1842-1847, 22 jan. 2016. 
NAKADA, L. Y. K. Avaliação da Qualidade de Água Pluvial Armazenadas e Estudos de Tratabilidade Empregando Filtro de Pressão Com Diferentes Meios Filtrantes Visando ao Aproveitamento Para Fins Não Potáveis. Bauru, 2012. 137 f. Dissertação (Mestrado em Engenharia Civil) - Curso de Engenharia Civil e Ambiental, Universidade Estadual Paulista "Júlio de Mesquita Filho”, Bauru, 2012.

TEIXEIRA, C. A. et al. Estudo Comparativo da Qualidade da Água Pluvial Coletada em Telhado Com Telhas de Concreto e em Telhado Verde Para Usos Não Potáveis. Ambiente Construído, Porto Alegre, v. 17, n. 2, p. 135-155, abr./jun. 2017.
VIEIRA, A. S.; WEEBER, M.; GHISI, E. SelfCleaning Filtration: a novel concept for rainwater harvesting systems. Resources, Conservation and Recycling, v. 78, n. 1, p. 67-73, 1 set. 2013.

WANG, J. et al. Pollutants Removal from First Flush by Filtration through Four Filter Media. In: INTERNATIONAL CONFERENCE ON BIOINFORMATICS AND BIOMEDICAL ENGINEERING, 4., Chengdu, 2010. In: INTERNATIONAL CONFERENCE ON BIOINFORMATICS AND BIOMEDICAL ENGINEERING, 4., Chengdu, 2010.

Proceedings... Chengdu, 2010.

\author{
Leticia Dalpaz \\ Departamento de Engenharia Civil | Universidade Federal de Santa Catarina | Rua J oão Pio Duarte Silva, 241, Córrego Grande | \\ Florianópolis - SC - Brasil | CEP 88037-000 | Tel.: (48) 3721-4981 | E-mail: ledalpaz@hotmail.com

\section{Aline Eloize Borgert} \\ Departamento de Engenharia Civil | Universidade Federal de Santa Catarina | E-mail: alineborgert@gmail.com \\ J úlia May Vendrami \\ Departamento de Engenharia Civil | Universidade Federal de Santa Catarina | E-mail: juliamvendrami@gmail.com \\ Enedir Ghisi \\ Departamento de Engenharia Civil | Universidade Federal de Santa Catarina | Tel: (48) 3721-2115 | E-mail: enedir.ghisi@ufsc.br
}

\title{
Revista Ambiente Construído
}

Associação Nacional de Tecnologia do Ambiente Construído

Av. Osvaldo Aranha, 99 - 30 andar, Centro

Porto Alegre - RS - Brasil

CEP $90035-190$

Telefone: +55 (51) 3308-4084

Fax: +55 (51) 3308-4054

www. seer. ufrgs. br/ ambienteconstruido

E-mail: ambienteconstruido@ufrgs.br 